\title{
Brucella ceti and brucellosis in cetaceans
}

\section{Caterina Guzmán-Verri ${ }^{1}$, Rocío González-Barrientos ${ }^{2}$, Gabriela Hernández-Mora ${ }^{2}$, Juan-Alberto Morales ${ }^{3}$, Elías Baquero-Calvo ${ }^{1}$, Esteban Chaves-Olarte ${ }^{1,4}$ and Edgardo Moreno ${ }^{1,5 *}$}

\author{
1 Programa de Investigación en Enfermedades Tropicales, Escuela de Medicina Veterinaria, Universidad Nacional, Heredia, Costa Rica \\ 2 Servicio Nacional de Salud Animal, Ministerio de Agricultura y Ganadería, Heredia, Costa Rica \\ ${ }^{3}$ Cátedra de Patología, Escuela de Medicina Veterinaria, Universidad Nacional, Heredia, Costa Rica \\ ${ }^{4}$ Facultad de Microbiología, Centro de Investigación en Enfermedades Tropicales, Universidad de Costa Rica, San José, Costa Rica \\ 5 Instituto Clodomiro Picado, Universidad de Costa Rica, San José, Costa Rica
}

\section{Edited by:}

Thomas A. Ficht, Texas A\&M

University, USA

Reviewed by:

Mikhail A. Gavrilin, Ohio State

University, USA

David O'Callaghan, INSERM, France

\section{*Correspondence:}

Edgardo Moreno, Programa de Investigación en Enfermedades Tropicales, Escuela de Medicina Veterinaria, Universidad Nacional, Heredia, Costa Rica.

e-mail:emoreno@medvet.una.ac.cr
Since the first case of brucellosis detected in a dolphin aborted fetus, an increasing number of Brucella ceti isolates has been reported in members of the two suborders of cetaceans: Mysticeti and Odontoceti. Serological surveys have shown that cetacean brucellosis may be distributed worldwide in the oceans. Although all $B$. ceti isolates have been included within the same species, three different groups have been recognized according to their preferred host, bacteriological properties, and distinct genetic traits: $B$. ceti dolphin type, $B$. ceti porpoise type, and $B$. ceti human type. It seems that $B$. ceti porpoise type is more closely related to $B$. ceti human isolates and $B$. pinnipedialis group, while $B$. ceti dolphin type seems ancestral to them. Based on comparative phylogenetic analysis, it is feasible that the $B$. ceti ancestor radiated in a terrestrial artiodactyl host close to the Raoellidae family about 58 million years ago. The more likely mode of transmission of $B$. ceti seems to be through sexual intercourse, maternal feeding, aborted fetuses, placental tissues, vertical transmission from mother to the fetus or through fish or helminth reservoirs. The $B$. ceti dolphin and porpoise types seem to display variable virulence in land animal models and low infectivity for humans. However, brucellosis in some dolphins and porpoises has been demonstrated to be a severe chronic disease, displaying significant clinical and pathological signs related to abortions, male infertility, neurobrucellosis, cardiopathies, bone and skin lesions, strandings, and death.

Keywords: Brucella, brucellosis, Brucella ceti, marine brucellosis, cetacean, dolphin, porpoise, whale

\section{INTRODUCTION}

Members of the genus Brucella are Gram negative bacterial pathogens of mammals, including humans. Since the first discovery of a distinct Brucella species in an aborted fetus of a bottlenose dolphin (Ewalt et al., 1994), an increasing number of isolates from different cetaceans has been reported (Figure 1). Most of these isolates belong to different bacterial clusters with affinity either for dolphins, porpoises, and even whales. Exceptionally, a few of the cetacean isolates belong to a different group of brucellae organisms that preferentially infect seals and walrus (Maquart et al., 2009a). Following the brucellae nomenclature convention that traditionally names the species after their preferred hosts, the isolates from cetacean were first designated as Brucella maris (Jahans et al., 1997), then as Brucella cetacea (Cloeckaert et al., 2001) and finally corrected to Brucella ceti (Foster et al., 2007). The overall genetic structure of $B$. ceti, such as the presence of two circular chromosomes and the absence of plasmids as well as the general bacteriological characteristics are in tune with the classical pathogenic Brucella from land mammals. The isolates from pinnipeds were found to be distinct from B. ceti; accordingly, they were named Brucella pinnipedialis (Foster et al., 2007).

The presence of cetaceans in the seas and littorals is a significant indicator for the wellbeing of the oceans and gage the magnitude at which the marine resources are protected. Moreover, several cetaceans pointed out by the IUCN red list of threatened species ${ }^{1}$ have been diagnosed to be infected with Brucella (Figure 1). Therefore, brucellosis in cetaceans should be considered a relevant disease that jeopardizes conservation. However, due to the level of localism and migration of cetacean species, this infection is not considered within the brucellosis national disease control programs and is not officially estimated for epidemiological surveillance and control. It would be desirable that future conservation and management efforts would initiate on whales and dolphin species that occupy neritic waters. In these zones, the human activities are intense and more likely to affect cetacean populations and, consequently, to facilitate the spreading of brucellosis. Practices such as hunting and excessive fishing, as well as contamination with microorganisms and pollutants put at risk the food resources of cetaceans. These negative activities may promote clustering of different cetacean species in reduced areas where food is available, causing excessive competition and undernutrition. In course, all these conditions may increase the number of susceptible animals and favor the transmission of brucellosis within the same species and between different species of cetaceans. Since brucellosis is a reproductive disease, its prevalence in cetaceans may

\footnotetext{
${ }^{1}$ http://www.iucnredlist.org
} 


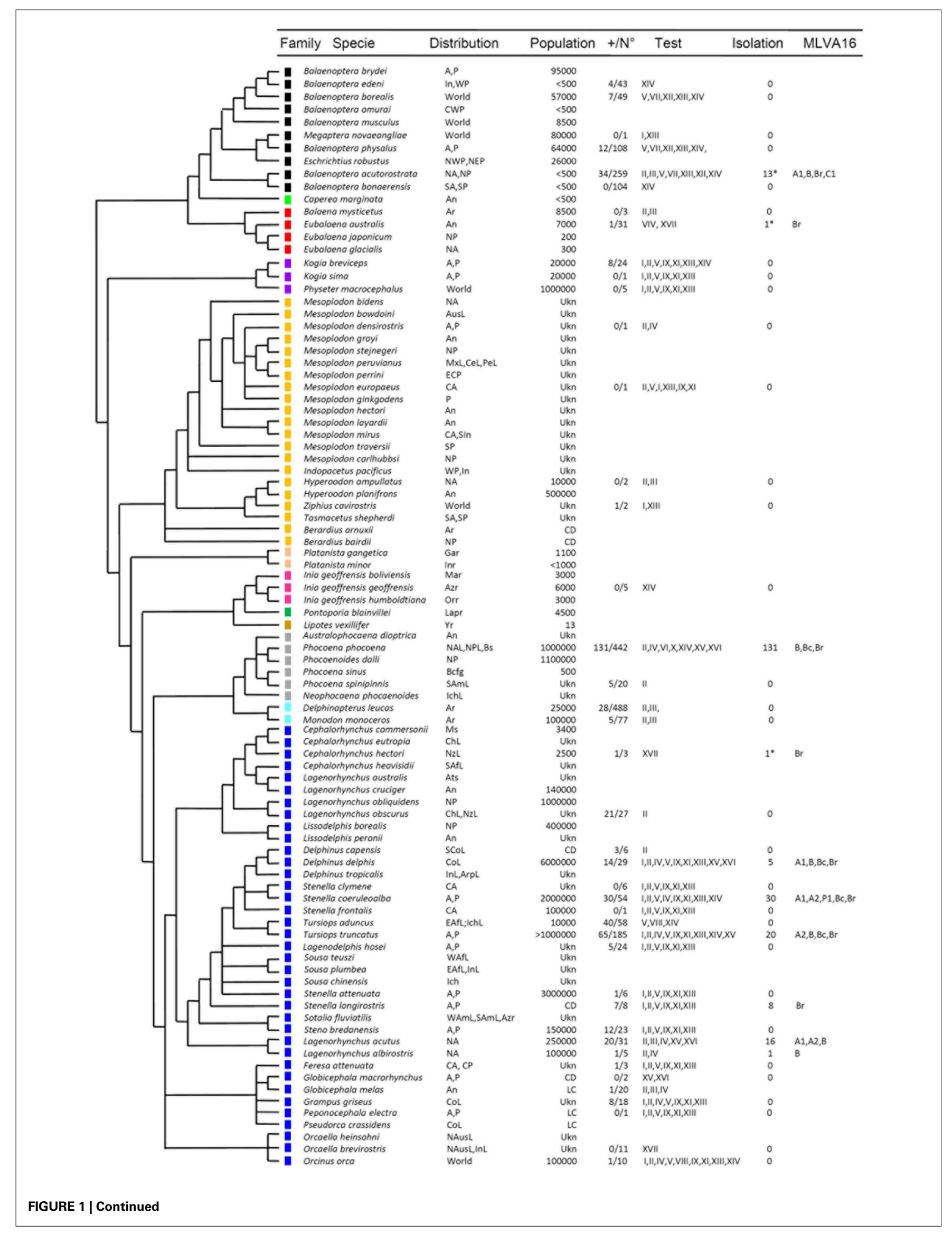




\section{FIGURE 1 | Continued Cetacean phylogeny in relation to Brucella infections. The} phylogenetic tree was constructed based in cytochrome B sequences as reported previously (May-Collado and Agnarsson, 2006). The species are named according to the current extant taxonomic rank. The color squares represent the different cetacean families as follows:

Balaenopteridae + Eschrichtiidae (black), Neobalaenidae (light green), Balaenidae (red), Kogiidae + Physeteridae (purple), Ziphiidae (yellow), Platanistidae (light pink), Iniidae (pink), Pontoporiidae (green) Lipotidae (brown), Phocoenidae (gray) Monodontidae (light blue), and Delphinidae (blue). The acronyms used for locating the oceanic distribution are the following: Africa (Af), Amazon River (Azr), America (Am), Antarctic Ocean (An), Arabic Peninsula (Arp), Arctic Ocean (Ar), Atlantic (A), Austral Sea (Ats), Australia (Aus), Baja California Gulf (Bacg), Black Sea (Bs), Central (C), Central America (Ce), Chile (Ch), Continental (Co), East (E), Europe (Eu), Ganges River (Gar), Indian Ocean (In), Indochina Sea (Ich), Indus River (Inr), Japan (Ja), La Plata River (Lapr), Littoral (L), Madeira river (Mar), Magellan Strait (Ms), Mediterranean Sea (Mes), Mexico (Mx), New Zealand (Nz) North (N), Orinoco river (Orr), Pacific (P), Pe (Peru), South (S), West (W), Worldwide (World), and Yangtze river (Yr). Population: The acronyms for the cetacean population size correspond to: least concern (LC), threatened (T), conservation dependent (CD). The number of serologically positive cetaceans in a given test/total number of cetaceans tested is indicated as $+/ \mathrm{N}^{\circ}$. The acronyms for the serological assays are: iELISA (I), cELISA-I (II), cELISA-II (III), aELISA (IV), gELISA (V), agELISA $(\mathrm{VI}), C^{\prime} E L I S A(V I I)$, Western Blot (VIII), Dot Blot (IX), FPA (X), IF (XI), Complement fixation (XII), Rose Bengal agglutination (XIII), Card agglutination test (XIV), Rivanol agglutination (XV), 2-mercaptoethan agglutination (XVI), PCR (XVII). Under "Isolation" refers to Brucella isolated from tissues of cetaceans. The MLVA-16 corresponds to A1, A2, $B, C 1$, and P1. The Brucella isolates not fully identified or only identified as $B$. ceti are indicated as $\mathrm{Br}$ and $\mathrm{Bc}$, respectively. Serological and bacteriological data obtained from (Ewalt et al., 1994; Ross et al., 1996; Jepson et al., 1997; Clavareau et al., 1998; Miller et al., 1999; Tryland et al., 1999; Nielsen et al., 2001; Van Bressem et al., 2001; Foster et al., 2002; Sabin et al., 2002; Maratea et al., 2003; Marvulo et al., 2003; Ohishi et al., 2003, 2007; Cowan, 2004; Duignan et al., 2005; Dawson et al., 2006; Omata et al., 2006; Tachibana et al., 2006; Alekseev et al. 2007; Manire et al., 2007; Hernández-Mora et al., 2008, 2009; Jepson and Deaville, 2008; Neimanis et al., 2008; Cisterna et al., 2009; Davison et al., 2009, 2011; Deaville and Jepson, 2009; Dove, 2009; Maquart et al., 2009a; Uhart et al., 2009; Di Guardo et al., 2010; González-Barrientos et al., 2010; Jauniaux et al., 2010; Meegan et al., 2010; Hernández-Mora et al., unpublished). * Determined by PCR. have a great impact in the population dynamics; particularly, if the low population growth rate of dolphins and whales is taken into consideration.

Cetaceans have great ecological and commercial value, since they are a fundamental part of the food chain and a source for protein and fat for many people around the world (Endo et al., 2005). In addition, whales, dolphins, and porpoises are an important tourist attraction in aquariums and littorals (Orams, 1997; Hoyt and Iñíguez, 2008) and dolphins are used in medical therapies (Antonioli and Reveley, 2005). One phenomenon that brings people in close contact with these attractive animals is the arrival to the shorelines of disoriented dolphins, porpoises, and whales displaying swimming problems. During the last years, these actions and contacts between cetaceans and humans have augmented worldwide (Malakoff, 2001; Brensing, 2004; Hernández-Mora et al., 2008) increasing the risk of transmission of pathogenic brucellae from these marine mammals to people and domestic animals (Figure 2).

Although Brucella strains of land animals have not been identified in cetaceans, the opposite is not true, and B. ceti strains have been isolated from human cases, stressing the potential zoonotic impact of these brucellae (McDonald et al., 2006; Whatmore et al., 2008). In spite of this and depending upon the strain, Brucella organisms isolated from marine mammals may display variable virulence (Ewalt et al., 1994; Rhyan et al., 2001; Perrett et al., 2004a; Maquart et al., 2009b). As other Brucella species, B. ceti seems to replicate inside host macrophages and trophoblasts and cause chronic diseases in cetaceans (González et al., 2002; HernándezMora et al., 2008; González-Barrientos et al., 2010); however, the mechanisms of pathogenesis, virulence, and host affinity have not been investigated. The smooth lipopolysaccharide (LPS) has been identified among the potential B. ceti virulent factors (Baucheron et al., 2002; Zygmunt et al., 2009). There are no significant differences in putative $N$-formylperosamyl transferase genes between the smooth strains isolated from marine and terrestrial mammals. In the Brucella marine strains the manBO-Ag carries an IS711, confirming its dispensability for perosamine synthesis (Zygmunt et al., 2009). Similarly, the partial sequence of B. ceti genome (Los Alamos National Laboratory and the Joint Genome Institute) demonstrates the presence of genes that code for virulent factors or their biosynthetic machinery, such as the Type IV secretion VirB system, the two component regulatory BvrR/BvrS system, cyclic $\beta$-glucans, the protein BacA, flagellum-like components, phosphatidylcholine, as well as many other genes involved in the intracellular survival of the classical virulent smooth Brucella abortus, Brucella melitensis, or Brucella suis (Roop et al., 2009). Within this context, cetacean brucellosis research may help to understand the evolution and natural history of this and other infectious diseases in open and migratory populations with worldwide distribution as well as the virulence and development of pathogenesis in a community that has not been vaccinated or treated with antibiotics.

\section{DIAGNOSIS OF BRUCELLA INFECTIONS AND CHARACTERIZATION OF B. CETIISOLATES}

In order to understand the natural history, dispersion, prevalence, epidemiology, and contagion sources of cetacean brucellosis in the oceans, it is necessary to apply diagnostic tests and, whenever possible, to isolate and identify the various Brucella strains. There are two types of assays that have been used for these purposes: direct identification methods and indirect screening tests. The first methods attempt to isolate the bacterium and then to characterize the microorganism. When bacterial isolation is not possible, there are other possibilities such as detection of specific Brucella DNA sequences by PCR or the direct visualization of bacterial antigens in tissues by immunofluroescence (IF), immunoperoxidase (IHRP), or immunoelectron microscopy. The indirect methods are assays devoted to detect antibodies in the sera of infected animals.

\section{DIRECT METHODS}

\section{Bacterial isolation and detection from infected tissues}

Brucella ceti strains have been isolated from members of the two extant suborders of cetaceans: Mysticeti and Odontoceti. The first 


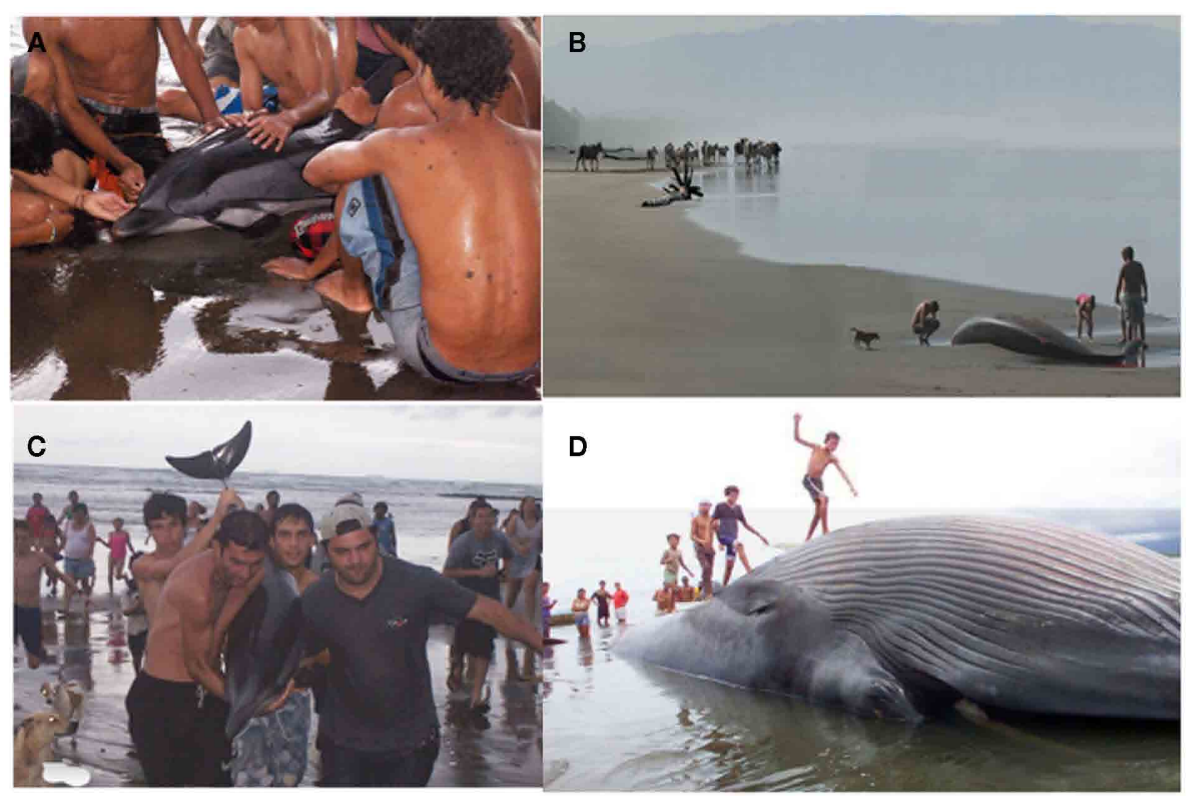

FIGURE 2 | Cetaceans in the Pacific coast of Costa Rica. (A) Alive stranded striped dolphin (S. coeruleoalba) with neurobrucellosis, attended by local inhabitants. (B) Death stranded Cuvier's beaked whale (Ziphius cavirostris) with positive Brucella serology in the shorelines where cattle (in the background) transits. (C) Alive striped dolphin (Stenella coeruleoalba) with neurobrucellosis being handled by tourists. (D) Dead stranded humpback whale (Megaptera novaeangliae; with permission, Grupo La Nación, Costa Rica). suborder includes four families of the so called baleen whales, comprising a group of large mammals whose vestigial teeth are lost before birth and therefore, lack functional teeth. The mysticetes are filter-feeders whose baleens are used to gulp-feeding (balaenopterids), skim-feeding (balaenids and neobalaenids), and bottom plowing (eschrichtiids). In contrast, the Odontoceti suborder groups 10 families of toothed cetaceans including dolphins, porpoises, sperm whales, river dolphins, narwhals, and beaked whales. B. ceti has been identified (by direct isolation or PCR) in just 4 out of 14 cetacean families; however, antibodies against Brucella antigens (mainly LPS) have been detected in members of seven of these families, indicating that Brucella infection is common in cetaceans (Figure 1). In spite of this, just a small number of the diagnosed cetaceans displays clinical or pathological signs associated with brucellosis, suggesting that a significant proportion of the infected animals overcome infection, with the possibility to remain as carriers and potential Brucella shedders. As expected, members of the Delphinidae family correspond to the most commonly Brucella infected cetaceans. The distribution of $B$. cet $i$ infections is almost worldwide, being the littorals of the North Atlantic Ocean the area with more reported cases (Figure 3).

Several body tissues and organs, either with or without associated gross or microscopic pathological changes, have provided Brucella positive cultures at some time. Isolations have been performed in free living, hunted animals, or in cetaceans confined to aquariums. However, the most frequent samples available come from stranded cetaceans in poor health conditions or already dead. Therefore, one important step that should always be included during the isolation procedures is the elimination of contaminants from surfaces. One alternative is to sear the surface of the tissue with a read-hot metal device or to immerse the entire tissue in 95\% ethanol and flame it for a few seconds. Surface decontaminated soft tissues or their internal sections can be homogenized in saline solution $0.9 \%$ within plastic bags, prior to plating into agar plates. Hard tissues can be cut with a sterile scalpel and samples taken from inside with swabs (previously soaked with saline solution) avoiding external surfaces. Fluids, such as cerebral spinal fluid, urine, or milk can be directly plated on agar plates or centrifuged to concentrate the bacteria prior plating. In the case of nematodes (which have been reported to contain Brucella, see below), they can be washed in sterile distilled water before maceration and culture. At this point, samples could be prepared for PCR testing or bacteriological cultures. If samples cannot be processed immediately, they may be frozen, if possible not more than 2 weeks, until further processing.

Every sample should be inoculated in a selective and nonselective media, since some strains may be inhibited by the components of the former media (Marin et al., 1996). Samples are preferentially plated on blood agar, serum dextrose agar, Columbia agar supplemented with $5 \%$ of sheep blood and Farrell's supplement (OXOID) or Brucella-agar supplemented with 5\% horse serum. Although most of the strains isolated from cetaceans are not capnophilic (Dawson et al., 2008b), primary cultures should be incubated in a $5-10 \% \mathrm{CO}_{2}$ atmosphere since a few strains have been reported to require this condition (Foster et al., 1996; Clavareau et al., 1998; Miller et al., 1999). It is expected that the majority of the B. ceti isolates will appear after 4 days of incubation (with and without $\mathrm{CO}_{2}$ ). Due to the fact that some primary cultures are slow growers, samples should be incubated for up to 14 days. Primary B. ceti isolates often fail to grow on 


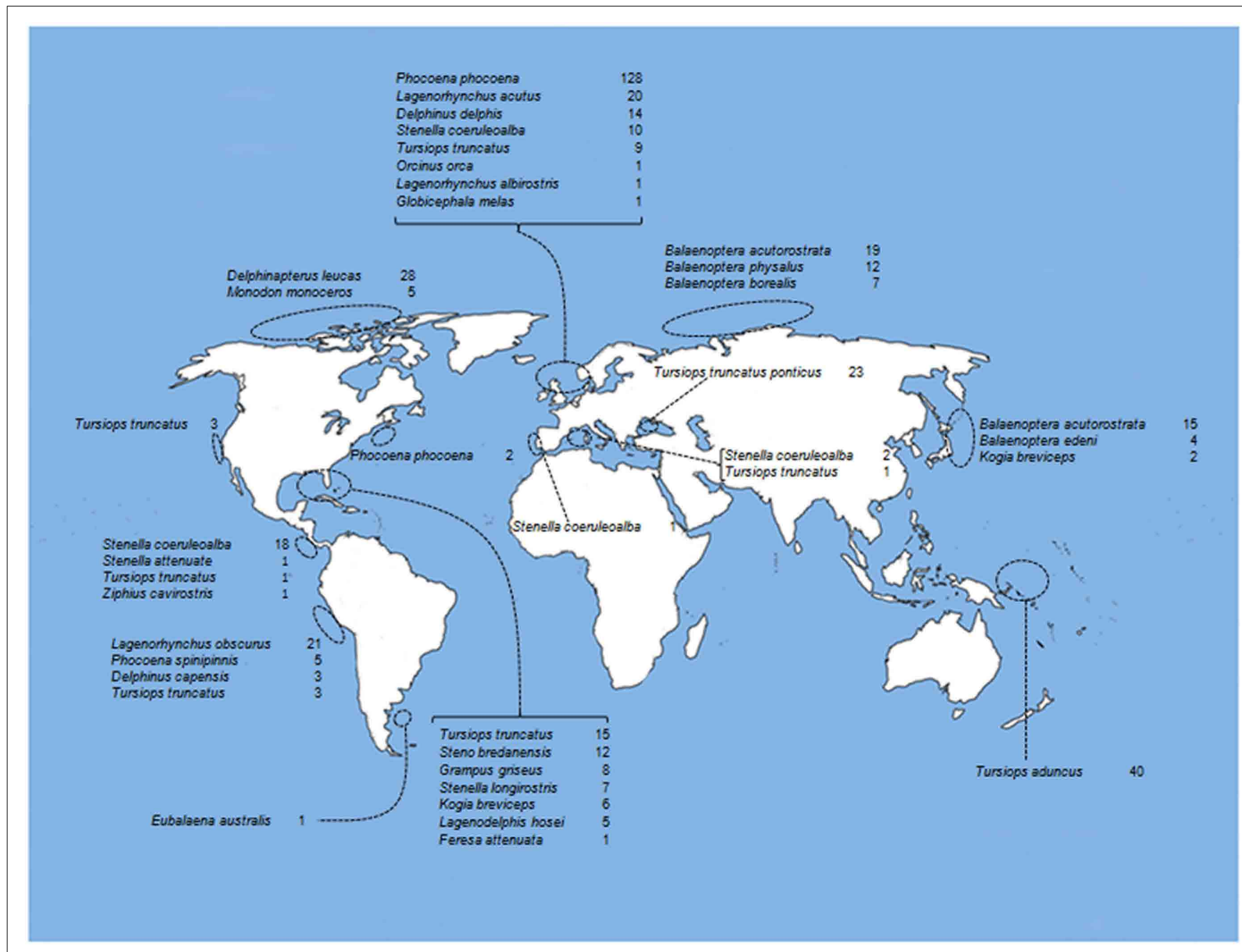

FIGURE 3 | Oceanic distribution of cetaceans with positive serological diagnosis for Brucella infections. References as in Figure 1.

a complete Farrell's medium; thus, it is recommended to exclude bacitrazin and nalidixic acid from the formulation (Foster et al., 2002).

Classical bacteriological biotyping techniques to identify phenotypic characteristics of the genus Brucella are not straightforward and some primary cultures from cetaceans may give anomalous results in some of the tests. Primary culture colonies are small and raised, convex and shiny, with an entire margin. When examined by transmitted light, they are honey colored and translucent. As other brucellae, B. cet $i$ primary isolates have the typical smooth (S) colony appearance of the genus. However, some primary cultures may rapidly dissociate and appear as rough phenotype (Foster et al., 2011; Guzmán-Verri et al., unpublished results). The appearance of the colonies are typical to other members of the genus, they are acid-fast in the modified Ziehl-Neelsen stain and agglutinate with anti-Brucella antisera in slide tests. Commercial kits normally used for bacterial identification not always include Brucella as part of the database, so special care should be taken when using these systems. Several bacteriological tests have been utilized to identify and characterize B. ceti (Table 1). However, $B$. ceti isolates are difficult to distinguish from $B$. pinnipedialis and therefore, clinical and epidemiological aspects must be taken into account, together with molecular techniques to complement classical biochemical characterization.

Brucella sp. is initially distinguished by standard bacteriological tests such as: Gram negative staining (coccobacilli or short rods), growth properties (3-4 days, raised, convex, circular, and entire with a diameter of $0.5-1.0 \mathrm{~mm}$, non-hemolytic), oxidase $(+)$, urease activity $(+)$, motility $(-)$, nitrate reduction $(+)$, and growth on Simmons citrate (-; Alton et al., 1975). At the species level, $B$. cet $i$ isolates are typically identified by phage typing, $\mathrm{CO}_{2}$ requirement, $\mathrm{H}_{2} \mathrm{~S}$ production, urease activity, nitrate reduction, agglutination with monospecific serum $\mathrm{A}$ and $\mathrm{M}$ and dye sensitivity (Table 1). To describe and characterize B. ceti strains, several isolates have also been tested for oxidation of amino acids, carbohydrates, and one alcohol [L-alanine $(-), \mathrm{L}$-arabinose $(+)$, L-arginine $(-)$, L-asparagine $(-)$ meso-erythritol (variable) D-galactose $(+)$, L-glutamic acid $(+)$, L-lysine $(-)$, DL-ornithine 


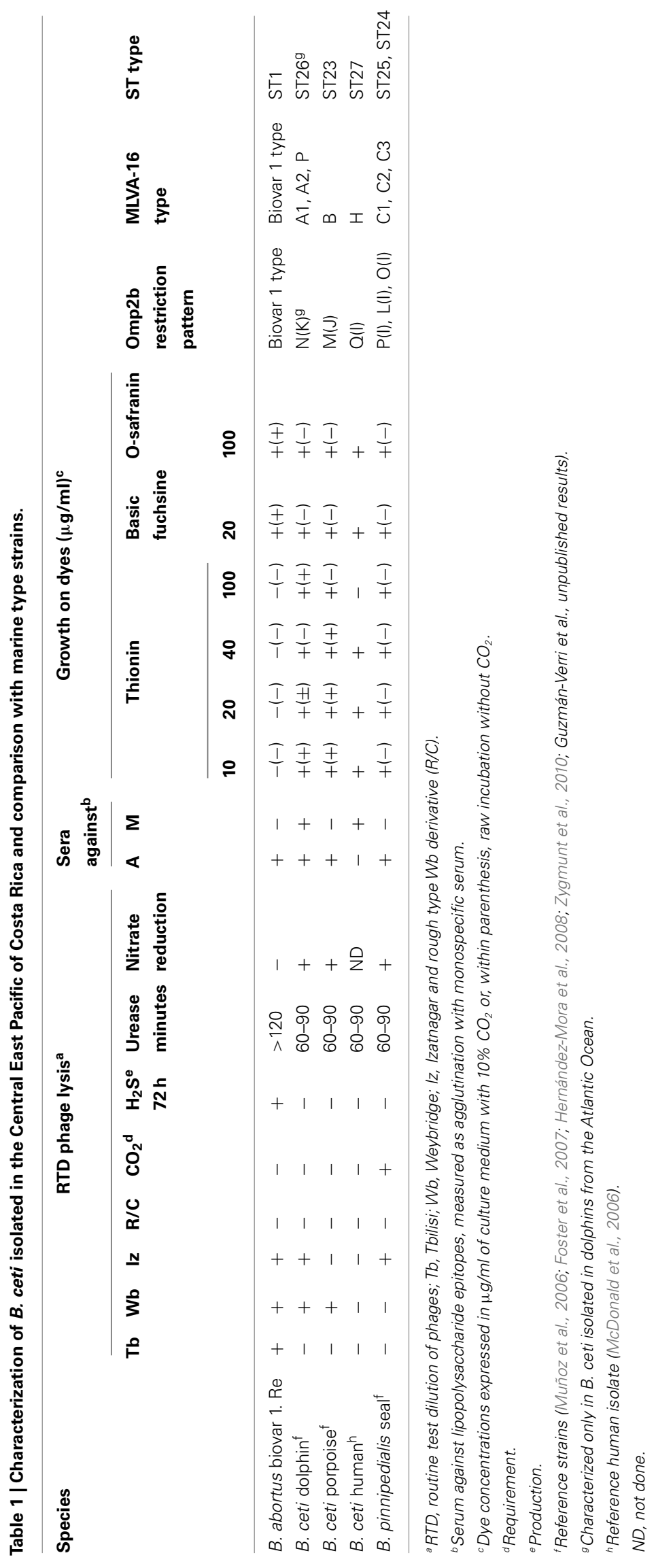


$(-)$, D-ribose (+), and D-xylose (+)] by conventional manometric techniques (Foster et al., 2007; Jacques et al., 2007).

\section{Molecular characterization}

There are several molecular methods that have been employed to characterize $B$. ceti isolates. The most used are the generation of PCR-restriction fragment length polymorphisms of genes coding for outer membrane proteins Omp2a, Omp2b, and Omp25 (PCR-RFLP-Omps), analysis of infrequent restriction sites-derivative PCR (IRS-derivative PCR), fingerprint profiles of insertion sequences IS711, multilocus sequence typing (MLST) to define the sequence type (ST) profile, and multiple loci variable number of tandem repeats analysis (MLVA). All these and other methods demonstrate good correlation and distinguish $B$. cet $i$ clusters that correspond to their preferred host: the $B$. cet $i$ dolphin type and $B$. cet $i$ porpoise type, and B. cet $i$ isolated from humans (Bourg et al., 2007; Dawson et al., 2008b; Zygmunt et al., 2010).

For the PCR-RFLP-Omps analysis, specific PCR products of Omp25, Omp2a, and Omp2b coding genes are digested with three different groups of restriction enzymes that discriminate among the various B. ceti isolates (Cloeckaert et al., 1995). The letters A through to $\mathrm{K}$ are assigned to represent the omp2a and omp2b profiles. Each letter represents a certain combination of restriction patterns with the group of restriction enzymes used. The lettering is consecutive and the profiles are named in the format $\mathrm{X}(\mathrm{Y})$, acronym that represents the combination of the individual restriction patterns of omp2a and omp2b genes with the omp2a gene profiles included within the parenthesis. Following this, the profiles generated for $B$. ceti correspond to the so called OMP $\mathrm{N}(\mathrm{K})$ and OMP $\mathrm{M}(\mathrm{J})$ and are idiosyncratic for the dolphin and the porpoise types, respectively (Dawson et al., 2008b).

For insertion sequence fingerprinting analysis, the mobile genetic element IS711 is used as a target for molecular characterization based on the number and distribution of IS711 copies within the Brucella genomes (Halling et al., 1993). Each profile generated comprises slightly more than 20 bands. As in the case of the PCR-RFLP-Omps profiles, the B. ceti fingerprinting IS711 patterns are idiosyncratic and show little resemblance to those of other Brucella strains (Zygmunt et al., 2010). For instance, members of IS711 cluster 2 correspond to OMP M(J), mainly associated with porpoises, while members of IS711 cluster 3 match with OMP $\mathrm{N}(\mathrm{K})$, associated to the B. ceti dolphin type.

The ISR-derivative PCR investigates the presence or the absence of four distinct PCR fragments in Brucella isolates (Cloeckaert et al., 2003; Zygmunt et al., 2010). Primers designed for PCR I are intended to recognize $B$. pinnipedialis isolates, while those designed for PCRs II, III, and IV contain portions of the IS711 element and seem to be specific for B. cet $i$ isolates. PCRs II and III are congruent with each other and with IS711 fingerprinting cluster 2, comprising mainly porpoise isolates. PCR IV is positive for $B$. cet $i$ isolated from dolphins corresponding to IS711 fingerprinting cluster 3 .

The MLST to define the ST profile, is a procedure that uses nine distinct Brucella genomic fragments of about 400-500 bp genes (Groussaud et al., 2007; Whatmore et al., 2007). For each interrogated locus, the different sequences present within a
Brucella strain are assigned as distinct alleles and, for each isolate, the alleles at each of the loci define the allelic profile or ST. According to this analysis, the $B$. ceti porpoise type belongs to the ST23, while the B. ceti dolphin (Atlantic) type to the ST26. The ST of the B. ceti dolphin type isolates from the Pacific Ocean has not been fully determined (Guzmán-Verri et al., unpublished results). The B. ceti isolates from human cases from New Zealand and Perú belong to a different ST category (ST27), together with an isolate from an aborted fetus from a bottlenose dolphin kept in an aquarium in San Diego, California (Whatmore et al., 2008; Cloeckaert et al., 2011). However, these isolates phylogenetically closer to the B. pinnipedialis group (Maquart et al., 2009a) are different from those recovered in dolphins from the Eastern Tropical Pacific Ocean in Costa Rica (Guzmán-Verri et al., unpublished results).

Multiple loci variable number of tandem repeats analysis is a technique that uses a family of multiple tandem repeats present in various loci in the Brucella genome. These tandem repeats, also known as microsatellites or minisatellites depending on the size of the repetitive unit, have proven to be very useful markers for Brucella strain typing and phylogenetic studies. For Brucella molecular typing there are at least three similar assays based in this principle (Bricker et al., 2003; Le Flèche et al., 2006; Whatmore et al., 2006). The MLVA based in a panel of 16 different markers (MLVA-16) has proved to be very useful in epidemiological studies. The markers are divided into two panels (labeled from Bruce 01 to Bruce30): the first comprises a cluster of minisatellite alleles that allows Brucella identification at species level; the second group consist of targets tandem repeats with higher mutation rate allowing higher resolution power and thus able to discriminate among strains (Le Flèche et al., 2006; Maquart et al., 2009a). Due to the clonal nature of the brucellae (Moreno, 1998), the MLVA are very useful to distinguish outbreaks. In addition, the MLVA-16 analysis is facilitated by the existence of a dedicated web service site for this purpose ${ }^{2}$. By this procedure the $B$. cet $i$ porpoise type has been characterized as a cluster B, while the B. ceti dolphin type as cluster A. This last cluster can be further subdivided in three subclusters: A1, A2, and P1. The first two subclusters represent $B$. cet $i$ isolates from dolphins inhabiting the Atlantic and Mediterranean Sea (Maquart et al., 2009a), while the P1 subcluster represent isolates from dolphins inhabiting the Eastern Tropical Pacific Ocean (Guzmán-Verri et al., unpublished results). The B. ceti isolate from a human case in New Zealand stands alone, in a MLVA-16 sister clade close to $B$. pinnipedialis cluster C (Figure 4). The Peruvian Brucella isolates from human cases seem to belong to the same MLVA group as the New Zealand strain (Cloeckaert et al., 2011).

\section{Detection of Brucella antigens in tissues by IF and I-HRP}

Detection of Brucella antigens by indirect IF from organs and tissues from suspected clinical cases of brucellosis is a rapid and efficient diagnostic tool. In spite of this, IF is seldom used in the diagnoses of brucellosis in cetaceans. In one report (HernándezMora et al., 2008), the cellular infiltrates from the cerebrospinal fluids from infected striped dolphins with neurobrucellosis were

\footnotetext{
${ }^{2}$ http://mlva.u-psid.fr/brucella
} 


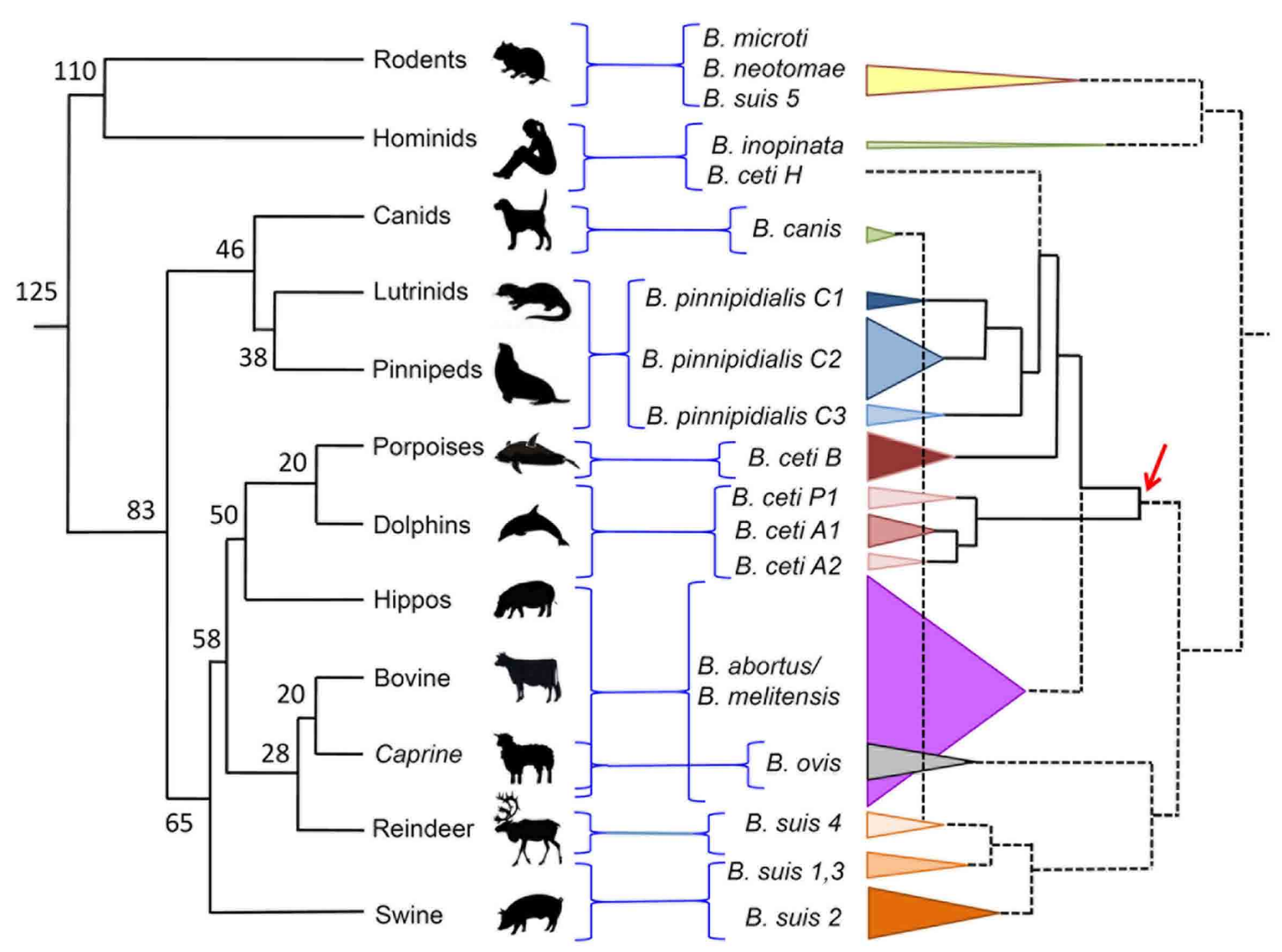

FIGURE 4 | Dispersion of Brucella species confronted to the phylogeny of their preferred host mammal. Phylogeny and time calibration of mammal evolution was adapted from (Kumar and Hedges, 1998; Bininda-Emonds et al., 2007). Brucella cladogram was estimated from MLVA-16 published values (http://minisatellites.u-psud.fr/MLVAnet/login.php?\&largeur=1680). The dispersion of the various Brucella species is depicted as cones proportional to the number of strains analyzed. The numbers in the mammal phylogenetic tree represent million of years. The arrow indicates the proposed dispersion of the clade that gave origin to $B$. ceti strains. Notice that according to this proposal, the $B$. ceti $B$ porpoise type is closer to the $B$. pinnipedialis $C$ clusters than to the $B$. ceti dolphin types $A 1, A 2$, and P1. B. suis biovar 2 also has affinity for hares (lagomorphs). processed by IF. The phagocytic cells present in these fluids displayed a clear positive signal indicating a reaction of the antibodies with Brucella related antigens that appeared as intact living bacteria as well as intracellular debris (Figure 5). In similar experiences, different organs (liver, spleen, kidneys, placenta, and fetal tissues) from which B. cet $i$ was isolated were first directly smeared on glass cover slips and processed by IF, giving a fast presumptive diagnosis of brucellosis (Hernández-Mora et al., 2008; GonzálezBarrientos et al., 2010). One disadvantage of performing rapid IF in non-stained tissues is that the topology and histology of the infected organs are not readily distinguished. For this, detection of Brucella antigens in histological sections of fixed tissues by the indirect I-HRP technique, is preferred (Figure 5). Indeed, successful identification of Brucella antigens by this method has been performed in the brain, heart, placenta, spleen, and testis of dolphins and porpoises (González et al., 2002; Dagleish et al., 2008; González-Barrientos et al., 2010; Jauniaux et al., 2010). As in IF, the main Brucella antigen detected by I-HRP in fixed tissues is the LPS. This is an advantage, since the Brucella LPS molecule is quite resistant to the denaturalizing procedures used during fixation and staining of histological sections. In spite of this, the I-HRP is time consuming and possesses relatively low sensitivity as compared to IF.

In the context of clinical cases, presumptive diagnosis of cetacean brucellosis performed by indirect IF or I-HRP, need to be interpreted with caution. There are several reasons for this; first, the high degree of auto fluorescence or intracellular peroxidase activity of mammalian tissues may hamper interpretation. The positive reactions should be based, not only on positive fluorescence or I-HRP staining, but on their association with bacterial morphology compatible with Brucella cells, debris, and tissue distribution. Second, it has been described that intracellularly growing Brucella reaches a state that is not detected by antibodies, thus IF or I-HRP detection might not be sensitive enough for diagnostic purposes. Even if B. ceti has been described as having smooth LPS, experiences from our and other laboratories (Foster et al., 2011; Guzmán-Verri et al., unpublished results) have indicated that this bacterium may appear as a rough phenotype. It is unclear whether this phenomenon depends on a rapid dissociation due to growth on in vitro conditions or to an atypically short O-chain. Since most of the antibodies used for brucellosis diagnoses are directed against smooth LPS, the chances that some 


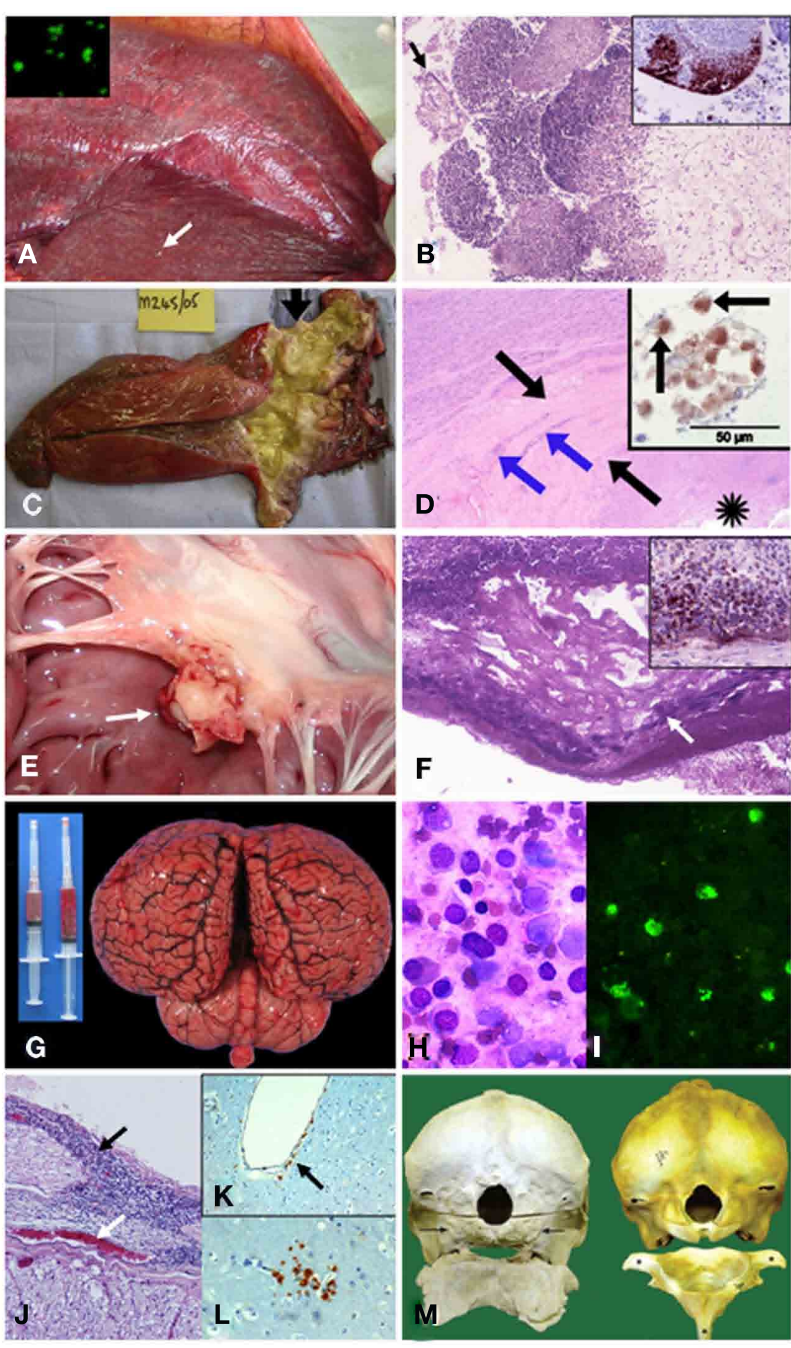

FIGURE 5 | Pathological findings in cetaceans with brucellosis. (A) Striped dolphin $S$. coeruleoalba fetus within placental presenting multiple necrotic foci diffusely distributed (arrow points a prominent focus); and, $B$. ceti detected by IF in impressions of placenta tissues (insert). (B) From (A) severe necrotizing placentitis showing detached placental cells (arrow) and marked necrosis of trophoblastic epithelial cells lining with infiltration of neutrophils into the fetal placental villi (HE stain 10x); and, I-HRP labeling of Brucella antigen within inflammatory cells invading the placental villi (insert). (C) Harbor porpoise P. phocoena right enlarged testicle (twofold) demonstrating an abscess and multi-locular lesions in the proximal area (arrow). From Dagleish et al., 2008, with permission, license $\mathrm{N}^{\circ}$

2756120153946). (D) From (C) HE histological section of the affected testis showing necrosis (asterisk), thick fibrous capsule of the abscess (black arrows) and the foci of mononuclear inflammatory cells (blue arrows); and I-HRP labeling of Brucella inside macrophage like cells (arrows) in the testicular lesion (insert). From Dagleish et al., 2008, with permission, license $N^{\circ}$ 2756120153946). (E) Vegetative nodule in the mitral valve (white arrow) of striped dolphin heart. (F) From (E) HE 10× histological section of the mitral valve showing bacterial colonies (arrow) intermixed within abundant fibrin deposits over the valve surface, focal areas of dystrophic calcification and severe suppurative inflammatory infiltrate surrounding this area. Insert shows positive I-HRP Brucella staining in inflammatory cells and bacterial aggregates (G) Hyperemic meningeal blood vessels in cerebral hemispheres and cerebellum from striped dolphin, showing cloudy

(Continued)

\section{FIGURE 5 | Continued}

and hemorrhagic cerebrospinal fluid in syringes. (H) Wright-Giemsa stained cells in cerebrospinal fluid from (G) composed of ependymal cells and mononuclear leukocytes. (I) IF of B. ceti and bacterial debris within phagocytic cells infiltrating cerebrospinal fluid shown in (H). (J) From (G) severe mononuclear inflammatory infiltrate in the meninges (black arrow) surrounding the spinal cord and hyperemic blood vessel (white arrow). (K) I-HRP labeling of Brucella antigens in cells that seem to be perivascular macrophages or pericytes laying below the endothelium of a vessel of the brain of striped dolphin (arrow), with no inflammatory response (courtesy of M. Barberán, Servicio de Investigación Agraria-DGA, Zaragoza, Spain). (L) I-HRP labeling of Brucella antigens in cells that seem to be macrophages or glial cells in the parenchyma of the brain of striped dolphin (courtesy of $M$. Barberán, Servicio de Investigación Agraria-DGA, Zaragoza, Spain). (M) Skulls (caudal view) and atlas bones (cranial surface view) of the affected Atlantic white-sided dolphin L. acutus (left) and the normal counterpart (right). The occipital condyles are completely absent in the affected animal (arrows), and only a roughened surface remains, which extends beyond the normal margins where these structures should be. There is also a lack of dorsal and lateral vertebral processes and normal smooth bone architecture, as well as a large amount of remodeling, present in the atlas bone. From Dagleish et al., 2007, with permission, license $\left.N^{\circ} 2756130134008\right)$.

replicating bacteria would not be detected by IF or I-HRP methods remain as an alternative. Finally, the possibility of cross reactions with other microbial products (e.g., perosamine containing molecules), may also be a source of misinterpretation. Additional and independent evidences, such as bacterial isolation or detection of positive serological reactions are necessary for corroborating IF and I-HRP results.

\section{SEROLOGICAL METHODS}

The presumptive diagnosis of Brucella infections is based in the detection of serum antibodies. Although serological techniques may not be specific for $B$. ceti infections, these methods are particularly useful for epidemiological and surveillance studies. The marine brucellosis serological diagnosis is not straightforward and requires a collection of positive and negative certified sera in order to determine the performance of the assays (Hernández-Mora et al., 2009). However, to accomplish this with a considerable number of cetacean species distributed worldwide is not easy. Indeed, the Odontoceti includes nine families with approximately 73 different species and the Mysticeti, four families with a total of 10 extant species (Nikaido et al., 2001; May-Collado and Agnarsson, 2006). Accordingly, over 15 different assays have been freely used for detection of anti-Brucella antibodies in cetaceans (Figure 1) and positive serological reactions have been already recorded in 23 out of 38 species tested worldwide (Figure 3 ). In spite of this, significant variations in predictive specificities and sensitivities of the various serological methods have been demonstrated (Hernández-Mora et al., 2009).

As those methods used for ruminant and human brucellosis, the principle of most Brucella serological tests used in cetaceans, also rest in detection of antibodies against LPS; specifically those directed to the $\mathrm{N}$-formyl perosamine determinants (Díaz-Aparicio et al., 1993, 1994; Baucheron et al., 2002). However, perosamine sugars are widely distributed in Gram negative bacteria, including several marine strains (Kondo et al., 2000; Awram and Smit, 2001), a fact that should be taken into consideration 
when confronting false positive reactions. The most frequently used assays are the competitive ELISA (cELISA), indirect protein G ELISA (gELISA), and agglutination assays (Figure 1).

Due to the fact that they are envisioned as straightforward and species-independent, direct methods such as agglutination assays are widely used (Neimanis et al., 2008). These assays are inexpensive, practical, easy to perform, and usually do not fail to detect antibodies in cetaceans with proven Brucella infections. In addition they are commercially available. Agglutination tests are, however, prone to give false positives due to cross reactions with bacterial antigens from other alpha-Proteobacteria infecting cetaceans (Delpino et al., 2004; Harms et al., 2008). In addition, the use of plasma or heavily hemolyzed sera may also cause false positive reactions, a fact that is not uncommon in stranded cetaceans. In spite of these drawbacks, agglutination methods remain robust and their use as primary screening tests is highly justified. Other direct assays, such as the fluorescence polarization (FPA) based on the displacement of photon emission after antibodies bind to a soluble $\mathrm{O}$-chain covalently linked with a fluorochrome, have been occasionally used (Neimanis et al., 2008). Although the FPA reagents are stable and the test can be automated, the assay requires standardized regents and specialized equipment, not always available in low income countries.

Three different cELISAs have been used for the detection of anti-Brucella immunoglobulins in cetaceans (Nielsen et al., 2001; Meegan et al., 2010). The advantage of these competitive assays is that they should be independent of the species where the serum was taken from, and thus applicable to the diagnosis of brucellosis in different mammals. In addition, they may be automated and at least one of them is commercially available. The cELISA has been adapted using LPS and whole bacteria antigens (Figure 1). In comparative experiments with odontocete sera, the cELISA using LPS as antigen showed more variable results and lower sensitivity and specificity than the iELISA that uses anti-odontocete IgG (Hernández-Mora et al., 2009). The whole-bacterial antigencELISA seems to have good sensitivity but low specificity and when compared with agglutination assays these competitive tests render fewer positives (Meegan et al., 2010).

The indirect ELISAs that use protein G (gELISA), A (aELISA), or recombinant A/G (agELISA) as "collective" IgG binding reagents have been extensively used for diagnoses of Brucella infections in cetaceans. As a general property, these ELISAs are straightforward and easily automated. In addition, the required reagents are stable and commercially available; furthermore, the test sera may be used at high dilutions, precluding some of the problems related to the serum quality. They also have the advantage of detecting IgG bound to the Brucella LPS, independently of the animal species. However, in a comparative experiment using odontocete sera, the gELISA displayed lower sensitivity and specificity than other tests, including cELISA and iELISA (Hernández-Mora et al., 2009). Moreover, cELISA and aELISA may show inconsistent and dissimilar results when tested with sera from the same dolphins, including those with Brucella positive cultures (Davison et al., 2011). Binding of $A$ and $G$ proteins to $\operatorname{IgG}$ varies significantly according to the mammal species (Akerstrom et al., 1985). In the case of cetaceans, it has been observed that the affinity of protein
A for the bowhead whale Balaena mysticetus IgG is rather low as compared to the relatively stronger binding of the IgG from the bottlenose dolphin T. truncatus (Kronvall et al., 1970). Furthermore, the kinetics of protein $\mathrm{G}$ binding to cetacean IgG is considerable lower than to bovine IgG, and the reactivity of protein G-peroxidase with odontocete IgGs is very sensitive to buffer conditions (Figure 6). The reactivity and affinity of protein $G$ and recombinant protein $\mathrm{A} / \mathrm{G}$ to IgGs of different cetacean species have not been determined. Therefore, the use of these reagents as "universal tools" has to be taken cautiously.

The advantages of iELISA using species-specific anti-IgG $(\mathrm{H}+\mathrm{L})$ conjugates for the detection of anti-Brucella antibodies in ruminants has been broadly documented (Díaz-Aparicio et al., 1993, 1994). The iELISA is straightforward, easily automated, the required reagents are stable and commercially available and the test serum can be readily diluted to eliminate unspecific reactions. In theory, the main limitation of the iELISAs lies on their restriction to a single or a few species, a fact that precluded their use $a$ priori for diagnostic purposes in Brucella infected cetaceans. In spite of this, two studies have already revealed broad cross reactions among Igs of different Odontoceti, allowing the use of antiserum raised against one species of dolphin as general reagent for detecting antibodies against different species of this suborder (Nollens et al., 2008; Hernández-Mora et al., 2009). It has been demonstrated that iELISA displays higher sensitivity and specificity, and is more consistent than cELISA and gELISA for the detection of antibodies against Brucella LPS in sera from 17 different odontocete species (Hernández-Mora et al., 2009). The superior performance of iELISA may lie in the broader avidity of polyclonal antiserum, which presumably recognizes an ample spectrum of epitopes in the heavy and light chains shared by the immunoglobulins of the various species of odontocete. Nevertheless, iELISA still has

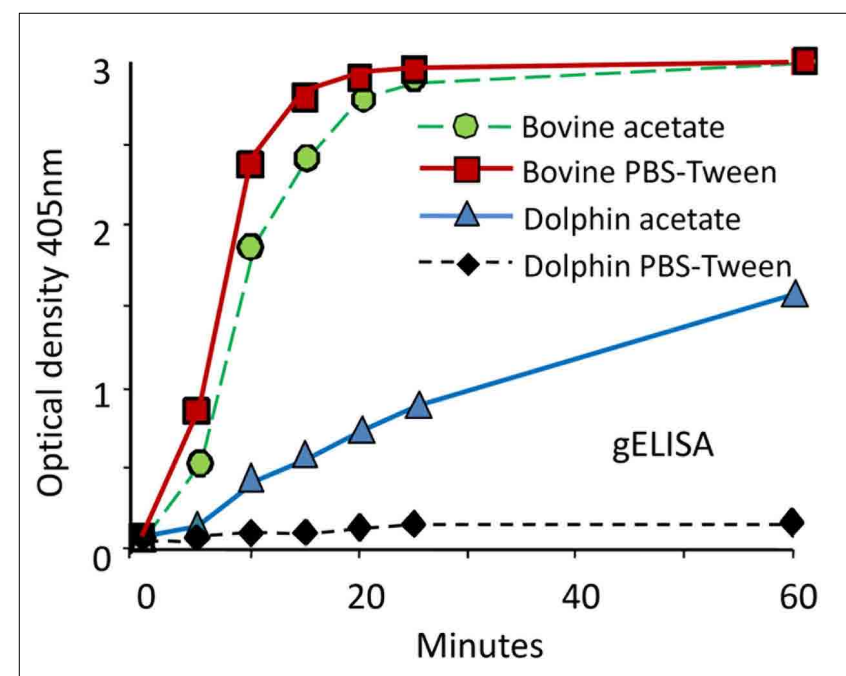

FIGURE 6 | Performance of protein G-HRP against odontocete sera and calibration of positive and negative controls. The performance of protein G-HRP in gELISA against sera from Brucella infected bovine (Bos taurus) and dolphin (S. coeruleoalba) was tested using two buffer conditions: PBS-Tween ( $\mathrm{pH} 7.7$ ) and $0.1 \mathrm{M}$ acetate buffer $(\mathrm{pH}$ 5). The SE at all points was $5 \%$ of the values (from Hernández-Mora et al., 2009, with permission). 
the limitation that anti-odontocete antibodies do not recognize immunoglobulins of mysticetes (Nollens et al., 2008). Therefore, one antiserum against baleen whales is necessary for detecting Brucella infections in mysticetes by iELISA.

Finally, CF assay has been sporadically used in the detection of brucellosis in cetaceans. In ruminants, this test has been the reference assay for many years. However, CF test is difficult to standardize, time consuming, and labor intensive. As an alternative, COMPELISA using complement in combination with a peroxidase-conjugated anti-C3 has been used for anti-Brucella LPS antibodies detection in cetaceans (Tryland et al., 1999). The linearity of this test with respect to complement titers in the diagnosis of ruminant brucellosis seems to be adequate. It also has the advantage of being independent of the animal species from which the assayed antibodies come from (Hinchliffe and Robertson, 1983; Hinchliffe, 1984). However, this assay has been of limited use and information regarding the binding of complement by cetacean immunoglobulins is not available.

\section{CETACEAN AND B. CETI PHYLOGENY AND HOST-PATHOGEN COEVOLUTION}

All B. ceti isolates have been included within the same species. However, according to their preferred host, bacteriological properties, and distinct genetic traits they can be further divided into three clusters: $B$. ceti dolphin type (A, ST26), B. ceti porpoise type (B, ST23), and $B$. ceti human type (ST27; Maquart et al., 2009a). In addition, cluster A can be subdivided in subclusters A1, A2, and P1, according to their MLVA-16 profiles (Figure 4). While most of the A1, A2, and B isolates come from cetacean species inhabiting the Atlantic Ocean, the P1 isolates come from a single species (Stenella coeruleoalba) stranded in the Eastern Tropical Pacific littoral of Costa Rica (Guzmán-Verri et al., unpublished results). Nevertheless, it is expected that other $B$. cet $i$ types from the Pacific Ocean would be present in cetacean species inhabiting these waters. The $B$. cet $i$ isolate from a human case in New Zealand does not group with any of these clusters (Figure 1). According to the MLVA-16 and the global population structure of the Brucella genus supported on more than 500 genotypes, observed by typing close to 750 strains (Maquart et al., 2009a), it seems that the B. ceti B porpoise type is more closely related to the $B$. ceti human isolate and the $B$. pinnipedialis group (Figure 4) and a sister clade of the B. abortus/B. melitensis cluster. As stated before, this proposal is sustained by the phylogenetic analysis of concatenated alignment of orthologous genes, by the position of the IS711 sequences, SpeI restriction profiles, and Omps porins in the various Brucella genomes (Bourg et al., 2007; Groussaud et al., 2007; Dawson et al., 2008b; Audic et al., 2011). By all these analysis, the clusters of the B. ceti dolphin type (A1, A2, and $\mathrm{P} 1$ ) seem ancestral to these three groups (Figure 4).

All cetaceans evolved from a common ancestor of the Raoellidae family of artiodactyls, a deer-like terrestrial herbivorous creature the size of a raccoon, which lived about 48 million years ago (Bajpai et al., 2009). The closest extant cetacean relatives are the hippopotamids followed by the ruminants (Figure 4). Although the former group has not been considered as a regular host of Brucella, there have been reports of brucellosis in these amphibian mammals (Guilbride et al., 1962). On the other hand, ruminants such as bovine, caprine, and ovine are among the most frequent terrestrial Brucella hosts.

Although there is a good agreement between the host and the Brucella species/biotype, the correspondence between the proposed radiation of mammal species and the Brucella phylogeny is not perfect (Figure 4). On the one hand, the cetacean/hippopotamus/ruminant group probably radiated from a common ancestor about 58 million years ago. On the other hand, the $B$. cet $i$ dolphin type (A1, A2, and $\mathrm{P} 1)$ seems ancestral to the $B$. abortus/B. melitensis/B. ceti porpoise type/B. ceti human type/B. pinnipedialis cluster. Thus, it seems feasible that the ancestor of this Brucella group radiated in terrestrial artiodactyl hosts close to the Raoellidae family, about the same time ( 58 million years ago). This is in good agreement with a previous proposal claiming that the divergence of the different species of the genus Brucella may have taken place 60 million years ago (Bourg et al., 2007). In the same line of thought, the Brucella ovis/B. suis (except biovar 5)/Brucella canis cluster may have radiated before, about 65 million years ago and the Brucella inopinata/Brucella microti/Brucella neotomae cluster, close to the root of mammal speciation, about 125 million years ago. Since carnivores such as pinnipeds (seals) belong to a different clade that separated from artiodactyls about 85 million years, it is feasible that the adaptation to seal hosts occurred after the separation of the B. ceti porpoise clade. Similar reasoning may be applied to the ancestor of $B$. cet $i$ human type.

The brucellae species exhibit a marked but not absolutely strict family host range. Nevertheless, the bacterium is seldom perpetuated in non-preferential hosts (Alton, 1990; Blasco, 1990; Carmichael, 1990; Meyer, 1990; Perrett et al., 2004a; Moreno and Moriyón, 2006), revealing that brucellae infecting secondary hosts are, in general, purged by natural selection. Indeed, in spite of the close genetic relatedness between the different brucellae members, there is strong correlation between genotypes and host ranges (Figure 4). Taking into consideration that many of the animals are intertwined in the oceans, this pathogen-host correspondence in natural populations of marine mammals is striking. For instance, it has been observed that harbor porpoises share diet with seals and dolphins (Santos and Pierce, 2003) and that dolphin "gangs" commonly attack porpoises (Ross and Wilson, 1996). In spite of these close contacts, only 12 out of 80 (15\%) reported Brucella isolates from dolphins correspond to the B. ceti B porpoise type. Similarly, from the $130 \mathrm{~B}$. cet $i$ isolates reported in porpoises, none of them belong to the dolphin type (Figure 1). A similar reasoning may be applied for the preference of $B$. pinnipedialis for seals walrus and sea lions. In the case of baleen whales, only three Brucella isolates have been reported: B. ceti porpoise type, B. ceti dolphin type, and $B$. pinnipedialis. The fact that the three isolates detected in mysticetes belong to three different Brucella types, suggests that these large mammals may be equally susceptible to either of the marine strains. However, the number of Brucella isolates in mysticetes is rather small and more strains are required to test this hypothesis.

The extant Brucella species seem to be of clonal nature, since they are commonly confined to the host environment with little chances of taking up heterogonous DNA (Moreno, 1998; Moreno et al., 2002). Indeed, the brucellae lack plasmids (genetic elements that confer the required plasticity for survival in open 
environments) as well as suitable structures for the transference of these genetic elements. Moreover, the chances for major genetic drifts are also reduced because of the stable selective pressures exerted by the internal environment of the host. These circumstances result in genetic diversity with more "tight" limits for the biological group. In the case of the B. ceti strains isolated from dolphins T. truncatus and Lagenorhynchus acutus, and from the porpoise Phocoena phocoena, it has been shown that more than one genetic MLVA-16 variant could be present in the same host (Maquart et al., 2009a), suggesting, at first glance, the occurrence of multiple infections in the same animal. Nevertheless, the close resemblance of these B. ceti strains (e.g., a few repeat unit changes in a single locus) suggests that mutational events in these variable regions occurred in the invading bacterial clone in the course of the infection (Maquart et al., 2009a). This phenomenon for generating diversity in clonal bacterial, such as Brucella, is not unexpected and has been predicted before (Moreno, 1998).

The Brucella members in general and B. ceti in particular, may correspond to a population structure reflecting an adaptation that does not exclude biological diversity. Then, the existence of several "ecotypic" species is not unexpected (Godreuil et al., 2005). This concept, confronts the mainstream of bacterial systematics which chief perspective is to view bacterial species as groups of organisms defined exclusively by phenotypic or molecular criteria. But this is not the only possible approach (Staley, 2006). Brucella species may alternatively be defined as entities having a set of dynamic (e.g., intracellular life and virulence) and stable (e.g., lack of plasmids) properties whose divergence is constrained by the close and stable environment of the host. Since the brucellae have been conceived as facultatively extracellular-intracellular parasites (Moreno and Moriyón, 2002), then, it is feasible to propose that the dispersion and divergence of this bacterial group (a phenomenon that we may call "speciation") is mainly restricted to the selective forces within the host environment and consequently to the evolution of the host. Nevertheless, this constrain is not perfect and in some cases the bacterium may "jump" to a different host specie, changing and adapting to a new environment, and in course, conforming a new Brucella strain or even a novel species (depending on the concept). Molecular clustering has successfully identified distinct $B$. ceti ecotypes inhabiting particular host families than in course could be assigned as different bacterial "species." Indeed the B. ceti porpoise type and dolphin type strains display specific affinities for two different family cetacean hosts, a phenomenon that parallels the host specificity observed in the Brucella counterparts from terrestrial mammals. Regarding the third party of B. ceti strains isolated from humans (Cloeckaert et al., 2011), more isolates from marine mammals with a distinct pathology are necessary before a conclusion can be drawn.

\section{TRANSMISSION}

It is intriguing how B. ceti strains are transmitted from infected individuals to susceptible hosts. The brucellae are non-motile and commonly do not stand harsh conditions in open environments (Moreno and Moriyón, 2006). Although this has not been strictly investigated in Brucella strains isolated from marine mammals, it seems unlikely that $B$. ceti could survive for long periods outside the host. In addition, high dilutions in the sea may hamper transmission due to low infecting doses. One obvious alternative is that Brucella is transmitted by close contact between hosts, such as sexual intercourse or maternal feeding. Indeed, B. ceti has been isolated from the reproductive systems of infected cetaceans and from milk (Hernández-Mora et al., 2008; Maquart et al., 2009a; González-Barrientos et al., 2010). A second alternative corresponds to vertical transmission from mother to the fetus, a fact that is feasible, since fetuses and placenta from infected animals have been found to contain large quantities of Brucella (Hernández-Mora et al., 2008; Maquart et al., 2009a; GonzálezBarrientos et al., 2010). An extension of this may be horizontal transmission through infected aborted fetuses or placental tissues. Several cetacean species have been observed to assist births and to be in close contact with the new born calf and placental discharges. An inclusive alternative is the infection through ingestion of Brucella contaminated fish or helminth vectors (Dawson et al., 2008a). It has been observed that lung nematodes of the genus Halocercus and Pseudalius parasitizing infected dolphins and porpoises respectively may contain relatively large quantities of Brucella. However it is not known how these nematodes infect cetaceans. Some of these parasites seem capable to cross placenta and then be transmitted from the mother to the fetus (Dailey et al., 1991). Regarding transmission through fish, it has been reported that Brucella and Brucella-like organisms have been isolated from fish and are capable to replicate in these vertebrates (Gelev and Gelev, 1988; Salem and Mohsen, 1997; El-Tras et al., 2010). Alternatively, it may be that $B$. ceti cycles in both, nematodes and fish, opening in this manner the possibility of transmission through reservoirs.

\section{BRUCELLA INDUCED PATHOLOGY}

In most cases, Brucella strains have been isolated from stranded cetaceans in precarious health conditions or already dead (Davison et al., 2011). Thus, it is difficult to pinpoint which are the characteristic features primarily related to brucellosis and to determine the clinical and pathological signs directly related to Brucella infections (González-Barrientos et al., 2010). For instance, many of the stranded animals generally harbor parasites in various organs and commonly have different kinds of lesions. Although some of these injuries and parasitism may be related to primary diseases, others may be due to secondary causes, such as trauma produced during the stranding event or even to persistent organic pollutants (Davison et al., 2009, 2011; Oliveira et al., 2011). As expected, some of these pathologies may compromise the physiology and cause severe disease, such as pneumonia, meningitis, liver, or cardiac failure. Moreover, it is not uncommon to find other bacterial species or fungus in the same organs and tissues from which Brucella was isolated (González-Barrientos et al., 2010). Frequently, these microbes are assigned as "contaminants." Nevertheless, these organisms may also be primary pathogens, or at least opportunistic microorganisms that could produce superinfections in cetaceans already infected with $B$. ceti. In other cases, concomitant viral infections have been suspected. Therefore, the differential clinical and pathological diagnosis of brucellosis in cetaceans is not straightforward and requires detailed investigation.

A basic knowledge of the anatomy and physiology of cetaceans is essential for interpreting clinical and necropsy findings, especially for discriminating between pathological signs and 
physiological changes attributed to maturation and aging in marine mammals (Perrin et al., 2008). Cetacean anatomy is specifically designed to facilitate living entirely on and under water. For instance, the skin has a fat blubber layer that functions both to insulate and to store food reserves and the ears do not protrude from the body as in other mammals but are reduced to a pinhole opening or a membrane flush with the skin. The size disparity between mysticetes and their prey has been resolved by the development of baleen plates for filtering food from water that allows them to feed on plankton and small pelagic fish usually found between 100 and $500 \mathrm{~m}$. Odontocetes, on the other hand, with their powerful teeth eat relatively large and less abundant animals, ranging from calamari and fish to seals, penguins, and even other cetaceans (Barros and Clarke, 2008). The cetacean digestive system is characterized by a long alimentary canal (Mead, 2008). The esophagus is a long, thick-walled tube, whose size corresponds to about one quarter of the total body length. The stomach is compartmentalized resembling that of ruminants, but the organization is different functioning as a reservoir for food and a stepwise digester.

\section{BRUCELLA PATHOLOGY IN THE REPRODUCTIVE ORGANS}

Brucella ceti has been isolated from the reproductive organs of both males and female cetaceans. The reproductive system of cetaceans has some unique features (Miller, 2007). The teats, along with the sex organs of both sexes do not protrude from the body and the genitals are guarded behind slits. The penis and testes have evolved to be hidden within the abdominal cavity. The female cetacean genitalia are less different from that of a terrestrial mammal (Stewart and Stewart, 2008). Similar to ungulates the cetacean placenta is epitheliochorial; however, in contrast to bovids (but similar to swine) does not have cotyledons and it is extremely thin and covered diffusely with villi. The embryo is initially enclosed in hugely expansive delicate membranes. There is a large allantoic sac with no vasculature surrounding the amniotic cavity and the amnion is covered with a single layer of epithelium. The intrauterine position of the cetacean fetus allows the tail to deliver first (Reidenberg and Laitman, 2008). Cetaceans seldom have multiple births and as a rule they have only one offspring, generally delivered in the warmer months born every other year. The length of gestation is about 11-12 months and within 30 min of its birth the calf already swims. The body weight of the calf is proportional to the average size of the cetacean which corresponds between 2 and $6 \%$ of the total body weight of an adult animal (Reidenberg and Laitman, 2008). Lactation lasts $7-18$ months and the calf is nurtured with its mother's fat-laden milk (40-50\% fat) and is weaned in about $7-8$ months, entirely by the mother. Sexual maturity in females is reached around 4-14 years while in males between 8 and 15 years. Cetacean longevity is about 15-40 years and similar to ungulates most of them are social animals.

The first report of Brucella infections in female cetacean reproductive organs was made in bottlenose dolphins kept in aquariums in California (Ewalt et al., 1994; Miller et al., 1999). In these cases, placentitis and abortions due to Brucella infection was documented and the bacterium was isolated from placentas and several tissues from aborted fetuses. Since then, Brucella was isolated from the mammary gland of sperm whales and dolphins, suggesting invasion of resident macrophages in these organs (Foster et al.,
2002; González-Barrientos et al., 2010). In other case, concerning a common minke whale from the western North Pacific displaying positive serology, it was found that the animal had several nodular granulomas in the uterine endometrium (Ohishi et al., 2003). These lesions presented significant mononuclear infiltration and had epithelioid and giant cells, suggesting a pathology induced by Brucella invasion. Abortion due to $B$. cet $i$ was also suspected in a harbor porpoise $P$. phocoena stranded in the coast of Belgium (Jauniaux et al., 2010). Although, abortion was not unambiguously established in this animal, the female porpoise still had milk in the udder and the bacterium was isolated from brain and lungs and microscopically observed by electron microscopy in a genital ulcer. In addition, the left uterine horn was dilated displaying prominent congested blood vessels.

One conspicuous case of brucellosis was described in a pregnant striped dolphin stranded alive in the Eastern Tropical Pacific coast of Costa Rica (Hernández-Mora et al., 2008; González-Barrientos et al., 2010). In this animal Brucella was first observed by indirect IF and then isolated from a congested placenta (Figure 5A), umbilical cord, milk, allantoic, and amniotic fluids as well as in multiple fetal organs. A severe necrotizing placentitis and a dead fetus close to 7-month gestation were found in this pregnant animal (Figure 5A). The histopathological signs detected in the placenta of B. ceti infected dolphins (Hernández-Mora et al., 2008; González-Barrientos et al., 2010; Miller et al., 1999 resemble those observed in bovine and camelid placentas infected with B. abortus; Gidlewski et al., 2000; Carvalho-Neta et al., 2010). For instance, the caruncular crypts of the dolphin infected placenta were filled with necrotic debris and showed hyperemic blood vessels, multifocal necrosis of trophoblasts with loss of placental mucosa, intense inflammatory infiltrate of neutrophils and moderate infiltration of macrophages and lymphocytes and moderate submucosa edema (Figure 5B). Several bacterial colonies were mixed with cellular infiltrates in the superficial chorioallantoic stroma. Brucella antigens were evidenced by immunohistochemistry within the inflammatory cells in these necrotic regions, revealing the presence of large quantities of bacteria (Figure 5B). In spite of the recorded placental lesions, no significant pathological signs were observed in the striped dolphin fetus, a fact that is in contrast to what it is generally observed in Brucella infected ungulate fetuses (Hong et al., 1991; Xavier et al., 2009; Carvalho-Neta et al., 2010). As in terrestrial animals, Brucella strains from marine mammals also display tropism for the udder of cetaceans. Therefore it is not unexpected to isolate Brucella from milk (Maquart et al., 2009a; González-Barrientos et al., 2010).

The first descriptions of Brucella associated epididymitis and orchitis in cetaceans were performed in mature baleen and toothed whales (Ohishi et al., 2003, 2004, 2008). In general, the testicular pathological profiles observed, went along with those lesions recorded in the testes of Brucella infected bulls and rams (Campero et al., 1994; Marco et al., 1994; Rhyan et al., 1997). For instance, in minke and Bryde's whales the conspicuous testicular lesions were mainly characterized by granulomatous tissue with caseation and mineralization, and in some instances abscesses displaying caseous necrosis. Under the microscope, the orchitis were associated with proliferation of epithelioid or giant cells and mononuclear infiltration. In a few cases subacute and chronic purulent 
orchitis, accompanied with progressive purulent inflammation, containing significant numbers of polymorphonuclears and interstitial fibroblasts were confirmed.

Brucella associated epididymitis and orchitis has also been recorded in harbor porpoises and Bryde's whales (Foster et al., 2002; Dawson et al., 2008b; Ohishi et al., 2008; Maquart et al., 2009a). A detailed description of one case (Dagleish et al., 2008), demonstrated lateral testicle enlargement with the presence of multiloculated abscess with a thick fibrous capsule (Figure 5C). This was centered in the testicle adjacent to the head of the epididymis and extended into the latter. The abscess was lined by a diphtheritic membrane and contained pale yellow clear fluid of low viscosity with many small floccules of pus, from which Brucella was isolated. The thick mature fibrous capsule of the abscess was surrounded by multiple, occasionally coalescing areas of coagulative necrosis, some with mineralization. Scattered areas of fibrosis associated to necrotic foci replaced the normal architecture of both the seminiferous tubules of the affected testicular lobules and the immediately adjacent part of the head of the epididymis. Multiple, mononuclear cell infiltration were present in the fibrous tissue capsule of the abscess as well as in adjacent tissues, and azoospermia was evident (Figure 5D).

As stated before, the particular localization of the bacteria in the reproductive tract of both male and female cetaceans, strongly suggests the possibility of transmission through sexual intercourse and breast feeding. Similarly to what has been observed in ungulates with brucellosis, these possible transmission mechanisms may ensure the prevalence of both clinical and latent $B$. ceti infections in cetaceans.

\section{CARDIOVASCULAR SYSTEM}

Brucella ceti has been isolated from blood, pericardial fluids, and heart lesions in cetaceans (Maquart et al., 2009a; GonzálezBarrientos et al., 2010; Davison et al., 2011). Since the cardiovascular system of cetaceans is adapted for permanent swimming and diving (Ponganis, 2008a,b), it is expected that lesions in this system severely impair these activities. For instance, the blood volume of cetaceans is between 45 and $72 \%$ of body weight (human is 7\%) and the circulatory system is adapted to increased metabolic rates and controlled temperature exchange to allow prolonged deep dives. Cetaceans are able to handle the quick change in blood pressure because of a special adaptation called the retia mirabilia found underneath the ribcage, between the blowhole and dorsal fin area. The retia is a mass of blood vessels that act as a buffer, protecting the brain against a surge of blood during high blood pressure and against a lack of blood flow during reduced heart rates. The cetacean heart is distinctly flattened dorsoventrally and similarly to ungulates there is a moderator band spanning the right ventricle (Ochrymowych and Lambertsen, 1984). The augmented thickness of the right ventricle and the shape of the cetacean heart are adaptations to the hemodynamic changes and collapse of the thorax associated with apneic diving. The size of the heart great vessels, coronary vasculature, and ventricular walls indicate a physiologic and adaptive right ventricular hypertrophy.

Brucella associated cardiovascular lesions have been frequently described in humans (Al-Harthi, 1989; Cay et al., 2009) but seldom recorded in terrestrial natural hosts. Therefore, it is significant that one adult female striped dolphin with neurobrucellosis also displayed a conspicuous and severe endocarditis (GonzálezBarrientos et al., 2010), very similar to heart lesions described in humans (Rahman et al., 2001; Özbek et al., 2007). These findings were characterized by thickening of the mitral valve which displayed a vegetation nodule, containing large areas of fibrin adjacent to the surface of the mitral valve (Figure 5E). In these areas, the predominant infiltrate was characterized by lymphocytes and macrophages, with some conspicuous plasma and giant cells. The surface of the valve also showed scattered necrotic areas, presenting dystrophic calcifications, and bacterial colonies surrounded by polymorphonuclear cells (Figure 5F). Degeneration of myocardial fibers surrounded by foci of mononuclear cells and a milder cellular infiltrate and perivascular edema in some zones of the myocardium, mainly around blood vessels, accompanied the lesions. Fibrosis surrounding the pericardium, infiltrated with lymphocyte and plasma cells, was also present. Brucella antigens were detected by immunohistochemistry within inflammatory phagocytic cells and in bacterial aggregates infiltrating the myocardium (Figure 5F). It is feasible that this heart chronic lesion developed during months or even years, impairing heart function.

\section{CENTRAL NERVOUS SYSTEM}

Cetaceans are among the most intelligent animals, displaying a large brain that allows significant cognitive capabilities and echolocation (Oelschläger et al., 2010). With the only exception of humans, the brain to body mass ratio of most members of the suborder Odontoceti is greater than all other mammals. Although there are similarities in cortical cytoarchitecture and neurochemistry between cetacean and ungulate central nervous systems (Hof et al., 1999), the cetacean brain possesses additional specialized features evolved to live permanently in water. Thus, it is not unexpected that neurobrucellosis in cetaceans is associated with disorientation and primary standings (González et al., 2002; Hernández-Mora et al., 2008; Davison et al., 2009; González-Barrientos et al., 2010). Moreover, neurobrucellosis has not been recorded in bovine, caprine, ovine, swine, or canine hosts. Nevertheless, this syndrome is a relatively common feature in non-treated human brucellosis patients (Obiako et al., 2010), including some individuals infected with Brucella stains isolated from marine mammals (Sohn et al., 2003). Therefore, brucellosis in cetaceans may constitute an interesting model to understand how the bacteria is capable to cross the hematoencephalic barrier and invade the brain.

Most of brucellae identified as $B$. ceti, have been isolated from the brain and cerebrospinal fluids of harbor porpoises, white-beaked dolphins, white-sided dolphins, and, for the most part, stranded striped dolphins (Foster et al., 2002; González et al., 2002; Jepson, 2005; Muñoz et al., 2006; Dagleish et al., 2007, 2008; Hernández-Mora et al., 2008; Davison et al., 2009; González-Barrientos et al., 2010; Jauniaux et al., 2010). The relatively high number of this last species displaying neurological syndrome associated to Brucella infections along the Central American Pacific shorelines and in European littorals argues in favor of a higher susceptibility of striped dolphins to acquire neurobrucellosis. Among the most relevant clinical signs observed 
are opisthotonus, tremors, seizures, disorientation, and a general inability to maintain buoyancy. The gross pathological findings present in most cases are characterized by hyperemic meninges and brain, and cloudy cerebrospinal fluid with increased volume and cellularity (Figure 5G), mainly composed of ependymal cells and mononuclear leukocytes (Figure $\mathbf{5 H}$ ).

Microscopically, the lesions of the brain have revealed meningoencephalomyelitis characterized by chronic, widespread, nonsuppurative meningitis, particularly in the brainstem, spinal cord, medulla oblongata, but less so in the cerebral and cerebellar cortices, without deep penetration into the sulci. Degeneration of Purkinje cells and focal gliosis has also been observed. Perivascular necrotic foci with macrophages, gitter cells, and lymphocytes were recorded in some cases. The inflammatory infiltrates were generally composed of lymphocytes, plasma cells, and macrophages and moderate to severe fibrosis, with a general absence or reduced number of polymorphonuclear cells. Some of the phagocytic cells possessed large aggregates of Brucella antigens as revealed by IF (Figure 5I). Vascular damage, consisting of perivascular serum leakage and hemorrhages and, to a lesser extent, fibrinoid necrosis of the intima of arterioles, was commonly present in areas of severe mononuclear inflammation.

In most cases periventricular encephalitis with mononuclear infiltrate, accompanied by some necrotic areas adjacent to the parenchyma and loss of the ependymal lining have been observed (Figure 5J). Commonly, the lesions are widespread, affecting the neuropil surrounding the ventricles taking the form of perivascular cuffs, although some scattered foci of microgliosis have been found. Mononuclear choroiditis forming lymphoid follicles, periependymitis, and white matter necrosis and laminar necrosis of the cerebrocortical gray matter associated with inflammatory changes have been observed in some cases. In at least one striped dolphin neurobrucellosis case, I-HRP labeling revealed Brucella antigens associated to the blood vessels and in the foci of gliosis, where they appear to be located within phagocytic cells and also in the vascular endothelium (Figures 5K,L). Interestingly, in some of the vessels the Brucella antigen positive cells lay below the endothelial cells, with no inflammatory response (Figure 5K). These antigen positive cells may be perivascular macrophages or pericytes that have differentiated into phagocytic cells (Guillemin and Brew, 2004). In general there is little or no involvement of the neurons and no inclusion bodies or syncytia are present. This may be a difference with human neurobrucellosis. Indeed, in human cases granulomas and syncytia within the cortical neural tissue have been observed (Sohn et al., 2003; Ceran et al., 2011).

Findings similar to those of striped dolphins have been observed in the brains of a white-sided dolphin and a harbor porpoise displaying antibodies against Brucella; however, no positive Brucella immunochemical labeling was achieved (Jepson, 2005; Jauniaux et al., 2010). The brain of the white-sided dolphin showed a generalized non-suppurative meningoencephalomyelitis, with multiple inflammatory foci, especially in the cerebral cortex, consisting of microglia and occasional thin mononuclear cell perivascular cuffs, appearing lymphoid in character.

It is worth noting that viral and parasitic diseases have been reported to induce encephalitis in cetaceans, which may be confused with neurobrucellosis. Among the most conspicuous are viral encephalitis caused by Morbillivirus and Herpes, and meningoencephalitis caused by toxoplasma parasites (Kennedy, 1998; Dubey et al., 2007; Di Guardo et al., 2010; Soto et al., 2011). These infections cause non-suppurative encephalitis in cetaceans and gross pathological examination of the brain tissues may display some resemblance with neurobrucellosis. Generally, differential diagnosis of Morbillivirus and Herpes are carried out by specific identification of the viral antigens within inflammatory cells, neurons, glial cells and neuropil by I-HRP, viral isolation, and PCR. In the case of Toxoplasma parasites, cysts, and zoites are commonly present in the brain parenchyma, which may be confirmed by immunohistochemical labeling.

\section{BONES AND JOINTS}

The cetacean skeleton is quite unique among mammals (Harrison, 1975). With the exception of flippers, dorsal fin, and tail flukes, cetaceans are almost perfectly streamlined covered by a smooth skin of several layers. The skeleton of the pectoral flippers correspond to a shorter version of forelimbs of land mammals. This supports the theory that the cetacean ancestors once had four legs and walked in land. The tail flukes and dorsal fin of cetaceans have no skeletal support and correspond to outgrowths of skin and connective tissue with no paragon to any terrestrial mammalian structure. The flukes are connected to the body muscles by a complex set of ligaments and fibers. The telescoped cetacean skull is remarkable for the elongation of the face bones. The occipital bone forms the back of the skull with nasal, frontal, and parietal bones in between. Cetaceans have no neck and the cervical vertebrae have fused in most species, inhibiting the rotation of the head. The undulatory swimming of cetaceans is enabled by the reduced interlocking of the individual vertebrae and the development of large fibrous disks between them. As in other severe pathologies caused by $B$. ceti, it is expected that skeletal lesions of cetaceans that impair summing are also primary cause of strandings.

There have been several reports of $B$. cet $i$ isolated from lesions in the bones and joints of cetaceans (Foster et al., 2002; Dagleish et al., 2007; Galatius et al., 2009; Maquart et al., 2009a; GonzálezBarrientos et al., 2010). The first case of a bone lesion linked to cetacean brucellosis was from a harbor porpoise displaying a discospondylitis spinal wound of no clinical significance, and therefore, death was connected to a different cause (Foster et al., 2002). This suggests that non-fatal cases of cetaceans brucellosis, may still cause a long-standing disease, remaining chronic in several tissues, including bones. A juvenile case was observed in a male striped dolphin which, in addition to meningoencephalomyelitis, the animal also presented fibrinopurulent osteoarthritis with severe infiltration of the synovial joint by macrophages and neutrophils affecting the right scapulohumeral joint (González-Barrientos et al., 2010). However, the most conspicuous case was a severe atlanto-occipital joint lesion in a white-sided dolphin, from which Brucella was isolated in large quantities (Figure 5M; Dagleish et al., 2007). This bone lesion, associated with neurobrucellosis as the ultimate cause of death, was characterized by non-mobile inseparable atlantooccipital joint with remodeling of the occipital condyles and the atlas, and absence of the smooth subchondral bone found beneath 
the articular surfaces of synovial joins. The dorsal and transverse processes of the atlas were also severely affected together with the area of the occipital bone that forms the margin of the foramen magnum. A broad spectrum of similar joint bone lesions have been described in white-beaked dolphins, closely related species of white-sided dolphins (Galatius et al., 2009); however, in these animals the link with brucellosis was not straightforward and unambiguously proven. Brucella has been also isolated from the spine and vertebrae in harbor porpoises, again stressing the chronic nature of the disease (Maquart et al., 2009a). It is worth noting that one human case in New Zealand, displaying spinal osteomyelitis has been associated with a B. ceti infection (McDonald et al., 2006). These bone-joint lesions are not uncommon in secondary hosts such as humans brucellosis cases (Chelli-Bouaziz et al., 2008). With the solely example of occasional hygromas in cattle with brucellosis (Humphreys and Moore, 1941), joint lesions are rare in ungulates (Johnson et al., 1994).

\section{RESPIRATORY SYSTEM}

Brucella has been isolated from the lungs of various cetacean species; however, no clear linkage between Brucella invasion and pathology of these organs has been established (Tryland et al., 1999; Foster et al., 2002; Muñoz et al., 2006; Dagleish et al., 2008; Prenger-Berninghoff et al., 2008; Davison et al., 2009; GonzálezBarrientos et al., 2010; Jauniaux et al., 2010). The cetacean respiratory tract, which may be a primary source of Brucella infection, is quite different from terrestrial mammals and is designed to allow breathing in rhythm with its ordinary motion during swimming and diving (Warstzok, 2008). The oral cavity leads only to their digestive tract and their nares lead only to their respiratory tract. This specificity ensures that neither food nor water obstruct respiration. In contrast to land mammals, there are not turbinate bones located in the front of the rostrum, but rather the nares of cetaceans form as a blowhole located in dorsal position that leads through the trachea to the lungs. Exhalation of air takes place at the surface, and is accompanied by a cloud of vapor whose aerosols may be accompanied by expulsion of germs, including Brucella. Cetaceans are active breathers who must consciously exhale to initiate respiration and have control of their intercostal muscles, larynx, and blowhole and must actively use them when above the ocean's surface. This characteristic diverges from other mammals whose pneumotaxic and apneustic brain centers unconsciously control respiration. This means that anesthetized cetaceans simply stop breathing once they lose consciousness (McCormick, 1969).

Due to the fact that cetacean lungs are some of the first organs to be affected during impaired swimming, the association between the presence of Brucella organisms in this tissue and pathological findings is ambiguous and not straightforward. For instance, Brucella organisms have been isolated from clinically normal lungs of cetaceans with brucellosis (Foster et al., 2002). In several cases of neurobrucellosis in live dolphins (implicated as the primary cause of the stranding), the lungs did not show associated pathology (González-Barrientos et al., 2010). There have been cases in which Brucella was isolated from the lungs, but the primary cause of disease was associated to other causes, such as viral infections (Foster et al., 2002). Moreover, in several of these cases other microorganisms distinct of Brucella were also isolated from the lungs (Muñoz et al., 2006; Dagleish et al., 2007; Hernández-Mora et al., 2008; Davison et al., 2009). As expected, the respiratory distress associated to the stranding process which, generally generates severe lung congestion, complicates the panorama during brucellosis.

Frequently, lung inflammation seems to be associated to the presence of nematodes that parasitize the lungs of these cetaceans and from which Brucella has been isolated (Perrett et al., 2004b; Dawson et al., 2008a; Jauniaux et al., 2010; Davison et al., 2011; Oliveira et al., 2011). As expected, this super-infection may induce complex inflammatory reactions and pathological lesions generated, not only by the resident Brucella, but by the nematode parasites. For instance in one stranded harbor porpoise in which $B$. cet $i$ was isolated from the lungs, nematode infestation of the right ventricle and pulmonary blood vessels was associated with acute pulmonary thrombi, severe acute necrotizing pneumonia and interstitial subacute and chronic pneumonia with arteritis (Jauniaux et al., 2010). It is common to observe eosinophilic granulomas, containing neutrophils, eosinophils, and a few macrophages, mainly associated with parasitic lungworms (González-Barrientos et al., 2010).

Some of the lung pathologies observed in Brucella infected striped dolphins (González et al., 2002; Muñoz et al., 2006; González-Barrientos et al., 2010) display resemblance to human lung lesions associated with brucellosis (García-Rodríguez et al., 1989). The main lung lesions recorded in these dolphins are characterized by interstitial pneumonia and bronchopneumonia, bronchiolar microcalcifications, hyperemia, and small aggregates of leukocytes in the peribronchiolar connective tissue. The lung parenchyma may show fibromuscular hyperplasia of alveolar septa and areas of atelectasis. Focal lymphocytic infiltration has been documented in a few cases.

\section{RETICULOENDOTHELIAL SYSTEM, SKIN, AND OTHER ORGANS}

The immune system of cetaceans does not considerable differs from that of other mammals. However, there are some unique anatomical features in cetaceans that are relevant to understand the infectious processes (Beineke et al., 2010; Jaber et al., 2010). Similarly to other juvenile mammals, spleen extramedullary hematopoiesis is present in young cetaceans; but the size of the spleen is small in relation to ruminants $(0.02 \%$ of body weight as compared to $0.3 \%$ body weight), and several smaller accessory spleens are common. Cetaceans possess complex lymphoepithelial laryngeal glands and unique lymphoid structures in the anal canal (anal tonsil) as well as lymphoepithelial oropharyngeal tonsils with multiple branching crypts which correspond to a particular adaptation to the marine environment. As in swine, the lymph nodes show an "inverse architecture" with central location of lymphoid follicles. In contrast to ungulates, visceral lymph nodes of cetaceans are distinguished from the somatic lymph nodes by the presence of smooth muscle fibers within the capsule which are supposed to enable active movement and filtration of lymph fluid by capsular contraction. The total number and proportion of leukocyte populations in blood is more similar to that of humans than to ruminants, displaying larger ratio of neutrophil/lymphocyte. Antibody panels developed against bovine, porcine, human, and equine cytokines and leukocyte markers, extensively cross react 
with that of cetaceans, making these reagents useful for studying the immune response of these marine mammals (Beineke et al., 2010; Jaber et al., 2010).

Brucella has been isolated from tissues of the reticuloendothelial system such as lymph nodes, spleen, and liver as well as from blood, peritoneal fluids, kidneys, skin ulcers, and sub-blubber abscesses of cetaceans (Foster et al., 1996, 2002; Clavareau et al., 1998; Muñoz et al., 2006; González-Barrientos et al., 2010; Jauniaux et al., 2010). Various pathological findings associated to brucellosis have been described in different tissues and organs. The most frequent are: hepatomegaly, splenomegaly, and lymph node enlargement, appearance of necrotic foci in the liver and spleen, inflammatory infiltration of the spleen, lymph nodes, and pancreas and congestion of kidneys. Although some of these signs are reminiscent of those found in human brucellosis (Spink, 1956), there is uncertainty on the primary origin of these lesions, since they could not be directly linked to Brucella parasitism. Nevertheless, in some of these tissues, Brucella antigens detected by I-HRP staining have been observed within the cytoplasm of mononuclear cells infiltrating the organs.

\section{DISCUSSION}

It has not been possible to establish the prevalence of Brucella infections in cetaceans. This is mainly due to two different shortcomings: (i) the diversity of serological assays used in the diagnoses of Brucella infections that do not preclude false positives and negatives, and (ii) the absence of systematic sampling. Indeed, most analyses of sera have been carried out from stranded or injured cetacean species whose primary cause of stranding or death is commonly unknown (Foster et al., 2002; González-Barrientos et al., 2010). In other cases sera has been obtained from hunted animals. All these factors generate significant biases in the diagnosis of Brucella infections in natural cetacean populations. In spite of these drawbacks, it seems clear that brucellosis is distributed worldwide in the oceans affecting a broad spectrum of cetacean species. There are, however, still several oceanic areas, seas and rivers as well as cetacean species in which Brucella infections have not been detected or investigated. For instance, there is only one report in the Antarctic Sea and very few studies in most regions of the Pacific Ocean and in river dolphins in South America, and no studies in Indian or China rivers, or in the Gulf of California, Indian Ocean, or South Atlantic Sea (Figure 3).

Since the first isolation of a Brucella strain from a bottlenose dolphin (Ewalt et al., 1994), the diversity of B. ceti organisms has increased and is in tune with the multiplicity of strains of Brucella species from terrestrial mammals and pinnipeds (Le Flèche et al., 2006; Maquart et al., 2009a). Since brucellosis in the oceans correspond to a malady affecting natural populations displaying broad range of movement and intertwining, it is therefore expected that description of new $B$. cet $i$ variants and pathologies will increase. The prediction is that the diversity of $B$. cet $i$ strains will exceed that of classical Brucella from domestic animals. In the case of B. abortus, B. melitensis, B. canis, B. ovis, and some strains of B. suis, the process of domestication of their respective hosts, along to the brucellosis control programs, may have narrowed the diversity of the extant classical species prevalent in cows, goats, sheep, dogs, swine, and reindeer. It is likely that these processes have selected for the more persistent Brucella variants. Indeed, some of the B. abortus biotypes and biovars described several decades ago (Meyer, 1990; Moreno and Moriyón, 2006) have not been reported for most than 40 years, a fact that seems to be in agreement with the reduction of diversity of the bovine bacterial strains.

Although not straightforward, comparative analyses suggest that some cetaceans species are more susceptible to Brucella infections than others. Among the odontocetes the harbor porpoise $P$. phocoena, striped dolphin S. coeruleoalba, white-sided dolphin $L$. acutus, bottlenose dolphin T. truncatus and the common dolphin Delphinus delphis seem to be the species with higher frequency of infections; while among the mysticetes, the northern minke whale Balaenoptera acutorostrata is likely the most affected species. With the exception of this last whale species, the above listed cetaceans are among the most prevalent (Figure 1), a fact that may bias the infection frequency. At least in odontocete brucellosis, gender or age differences do not appear to be relevant (Hernández-Mora et al., 2009).

Several cetaceans with positive serology or even with positive Brucella cultures do not show obvious clinical signs or associated pathology (Foster et al., 2002; Hernández-Mora et al., 2009). In some cases, the infection is reminiscent of what has been recorded in ungulates and dogs (e.g., epididymitis and placentitis). However, in other cases cetaceans show conspicuous clinical signs and pathological lesions seldom observed in natural hosts, but reminiscent of those recorded in humans. In harbor porpoises and striped dolphins severe Brucella associated pathologies at the level of heart, joints, skin, brain, and bones, have been recorded. These pathologies indicate that $B$. ceti is capable to cause longlasting and deadly infections in at least some of these cetaceans (Foster et al., 2002; González-Barrientos et al., 2010). Therefore, cetacean brucellosis may constitute a good model for understanding Brucella pathogenesis in non-treated and non-vaccinated populations.

Although the picture is far from being complete, it seems that some B. ceti genotypes are more virulent and better adapted to infect certain hosts than others (e.g., MLVA-16 clusters A1, A2, and $\mathrm{P} 1$ for dolphins and $\mathrm{B}$ for porpoises). Alternatively, it may be that all $B$. ceti strains are equally suited and equipped to infect different cetaceans, but that some host species are more susceptible to brucellosis than others. It may be that the predicted "host affinity" just corresponds to oceanic separation and not due to specific bacterial adaptation, a notion that does not contradict the concept of Brucella ecotypic speciation. In addition, both realities may coexist. On the one hand, it is known that B. ceti A1 and A2 type strains inhabit the same oceanic area, while P1 strains have been only found in the Eastern Tropical Pacific (Guzmán-Verri et al., unpublished results). Nevertheless, the three type strains cause a very similar neurobrucellosis syndrome in different populations of striped dolphins (Foster et al., 2002; Maquart et al., 2009a; González-Barrientos et al., 2010). On the other hand, the B. ceti A1 and A2 strains have not been isolated from porpoises which inhabit the same area as the Atlantic white-sided dolphin, but the opposite is not true (Maquart et al., 2009a). Moreover, the New Zealand B. ceti human isolate and each of the three isolates from the common minke whale $B$. acutorostrata belong 
to different MLVA-16 groups (Maquart et al., 2009a), complicating the scenery. More Brucella related pathologies and isolates from different latitudes and species are necessary before a clear panorama on B. ceti biology and cetacean brucellosis is foreseen.

There is growing evidence on the existence of toxic effects of environmental contaminants and on the immunosuppressive properties of xenobiotics in cetaceans (Beineke et al., 2010). In one study, $B$. ceti infections were associated to the presence of high levels of chlorobiphenyl in blubber of the dolphins (Davison et al., 2011). Therefore, it is possible that the negative influence of xenobiotics on the immune system may increase the susceptibility of the exposed cetaceans to Brucella infections. This may be more dramatic in endanger species whose brucellosis status has not been investigated, such "la vaquita" Phocoena sinus, living close to the shorelines of contaminated waters in the Pacific littoral of Baja California, Mexico (Reyes et al., 2002), or the South Asian River dolphin (Platanista gangetica) living in the contaminated waters of the Ganges and Brahmaputra rivers (Smith et al., 1998).

Despite of the few human cases attributed to brucellae isolated from marine mammals (Sohn et al., 2003; McDonald et al., 2006), the magnitude of the risk that B. ceti represents for humans remains unknown. Some authors argue that brucellosis from marine mammals may have been underestimated due to misdiagnosis and underreporting, mainly in low income countries (Van Bressem et al., 2009). However, the limited assays performed with $B$. cet $i$ in cows and rodents suggest that they are less virulent than ruminant brucellae (Rhyan et al., 2001; Perrett et al., 2004a). Most of the massive cetaceans killings done by humans (Ohishi et al., 2008; Van Bressem et al., 2009) are performed without any protection in business enterprises from high income countries (in which medical assistance and diagnosis are highly sophisticated). In spite of this, no cases of brucellosis have been reported in these workers. No health problems associated with brucellosis or Brucella-specific antibodies were found in 154 crew members and researchers having frequent contacts with cetaceans (Ohishi et al., 2008). Similarly, a limited survey performed in humans inhabiting the Pacific littorals of Costa Rica (in which stranding due to neurobrucellosis have been recorded) did not reveal the presence of antibodies against Brucella antigens (Guzmán-Verri et al.,

\section{REFERENCES}

Åkerstrom, B., Brodin, T., Reis, K., and Björck, L. (1985). Protein G: a powerful tool for binding and detection of monoclonal and polyclonal antibodies. J. Immunol. 135, 2589-2592.

Alekseev, A., Yu, E., Rozanova, I., Ustinova, E. N., Tumanov, Yu. I., Kuvshinova, I. N., and Shestopalov, A. M. (2007). The prevalence of antibodies to morbilliviruses, Brucella, and Toxoplasma in the Black Sea bottlenose dolphin Tursiops truncatus ponticus maintained in captivity. Russ. J. Mar. Biol. 33, 425-428.

Al-Harthi, S. S. (1989). The morbidity and mortality pattern of Brucella endocarditis. Int. J. Cardiol. 25, 321-324.

unpublished results). This is significant, taking into account that many of the local inhabitants had contacts with these infected animals (Figure 2). Moreover, none of the veterinaries or scientific personnel that assisted the strandings, performed bleedings, participated in necropsies or bacteriological studies have seroconverted or demonstrated signs of brucellosis (Guzmán-Verri et al., unpublished results). Nevertheless, B. ceti qualifies as potentially dangerous bacterium for humans and land animals. Indeed, its phenotype corresponds to a smooth type of brucellae equipped with all known virulent factors and capable to induce severe chronic disease in cetaceans. After all, it seems that in most cases biology counts and that the subtle differences observed in the $B$. ceti genome keep these organisms out from infecting and causing disease in humans. But, the phylogenic pattern of Brucella in relation to host preference (Figure 4) suggests that the brucellae are capable to "jump" from one mammal order to a very differ one and eventually persist as a distinct Brucella clone and become a novel species in a new preferred host.

\section{AUTHORS CONTRIBUTIONS}

Edgardo Moreno, Caterina Guzmán-Verri, Esteban Chaves-Olarte, and Elías Baquero-Calvo, contributed in the writing of the manuscript. Rocío González-Barrientos, Gabriela Hernández-Mora, and Juan-Alberto Morales, contributed with collection and assemblage of the Figures. All authors contributed with discussions and revision of the manuscript.

\section{ACKNOWLEDGMENTS}

The authors thank Montserrat Barberán (SIA-DGA, Zaragoza, Spain) for some of the photographs of brain histopathological sections performed in Atlantic S. coeruleoalba with brucellosis; the KETO Foundation for their assistance with the stranded animals in Costa Rica. This work was funded by the following grants: FIDA-2006-UNA, UCR-Subdivision of Research, FS-CONARE-UNA/UCR/ITCR, FORINVES-FV-00107-MICIT/CONICIT, NeTropica 8-N-2008, and International Centre for Genetic Engineering and Biotechnology. This work was done as part of the UCR/DAAD Humboldt Fellow award 2012 to Edgardo Moreno.

11, 200. doi: 10.1186/1471-2148-11200

Awram, P., and Smit, J. (2001). Identification of lipopolysaccharide $\mathrm{O}$ antigen synthesis genes required for attachment of the S-layer of Caulobacter crescentus. Microbiology 147, 1451-1460.

Bajpai, S., Thewissen, J. G., and Sahni, A. (2009). The origin and early evolution of whales: macroevolution documented on the Indian subcontinent. J. Biosci. 34, 673-686.

Barros, B., and Clarke, M. R. (2008). "Diet," in Encyclopedia of Marine Mammals, 2nd Edn, eds W. F. Perrin, B. Würsing, and J. G. M. Thewissen (New York: Academic Press), 311-316.

Baucheron, S., Grayon, M., Zygmunt, M. S., and Cloeckaert, A. (2002).
Lipopolysaccharide heterogeneity in Brucella strains isolated from marine mammals. Res. Microbiol. 153, 277-280.

Beineke, A., Siebert, U., Wohlsein, P., and Baumgärtner, W. (2010) Immunology of whales and dolphins. Vet. Immunol. Immunopathol. 133, 81-94.

Bininda-Emonds, O. R. P., Cardillo, M., Jones, K. E., MacPhee, R. D. E., Beck, R. M. D., Grenyer, R., Price, S. A., Vos, R. A., Gittleman, J. L., and Purvis, A. (2007). The delayed rise of present-day mammals. Nature 446, 507-512.

Blasco, J. M. (1990). "Brucella ovis," in Animal Brucellosis, eds $\mathrm{K}$ H. Nielsen and J. R. Duncan (Boca Raton, FL: CRC Press), 352-378. 
Bourg, G., O'Callaghan, D., and Boschiroli, M. L. (2007). The genomic structure of Brucella strains isolated from marine mammals gives clues to evolutionary history within the genus. Vet. Microbiol. 125, 375-380.

Brensing, K. (2004). Approaches to the Behavior of Dolphins Tursiops Truncatus During Unstructured Swim-With-Dolphin Programs. Ph.D. thesis, Fachbereich Biologie, Chemie, Pharmazie, Freien Universität Berlin, Berlin.

Bricker, B. J., Ewalt, D. R., and Halling, S. M. (2003). Brucella "HOOF-prints": strain typing by multi-locus analysis of variable number tandem repeats (VNTRs). BMC Microbiol. 3, 15. doi:10.1186/1471-2180-3-15

Campero, C. M., Ladds, P. W., Hoffmann, D., Duffield, B., Watson, D., and Fordyce, G. (1994). Immunopathology of experimental Brucella abortus strain 19 infection of the genitalia of bulls. Vet. Immunol. Immunopathol. 24, 235-246.

Carmichael, L. E. (1990). "Brucella canis," in Animal Brucellosis, eds K. H. Nielsen and J. R. Duncan (Boca Raton, FL: CRC Press), 336-350.

Carvalho-Neta, A. V., Mol, J. P., Xavier, M. N., Paixão, T. A., Lage, A. P., and Santos, R. L. (2010). Pathogenesis of bovine brucellosis. Vet. J.184, 146-155.

Cay, S., Cagirci, G., Maden, O., Balbay, Y., and Aydogdu, S. (2009). Brucella endocarditis: a registry study. Kardiol. Pol. 67, 274-280.

Ceran, N., Turkoglu, R., Erdem, I., Inan, A., Engin, D., Tireli, H., and Goktas, P. (2011). Neurobrucellosis: clinical, diagnostic, therapeutic features and outcome. Unusual clinical presentations in an endemic region. Braz. J. Infect. Dis. 15, 52-59.

Chelli-Bouaziz, M., Ladeb, M. F., Chakroun, M., and Chaabane, S. (2008). Spinal brucellosis: a review. Skeletal Radiol. 37, 785-790.

Cisterna, C., Conde, S., Chirife, A., Salustio, E., Hollender, D., Cantero, J. G., Wei Ling, Y. U., and Samartino, L. (2009). "Brucellosis diagnosis in marine mammals using PCR," in 62nd Annual Brucellosis Research Conference (As a Satellite Meeting of CRWAD), December 5-6, Chicago, IL.

Clavareau, C., Wellemans, V., Walravens, K., Tryland, M., Verger, J. M., Grayon, M., Cloeckaert, A., Letesson, J. J., and Godfroid, J. (1998). Phenotypic and molecular characterization of a Brucella strain isolated from a minke whale (Balaenoptera acutorostrata). Microbiology 144, 3267-3273.

Cloeckaert, A., Bernardet, N., Koylass, M. S., Whatmore, A. M., and Zygmunt, M. S. (2011). Novel IS711 chromosomal location useful for the identification of the marine mammal Brucella genotype ST27 associated with zoonotic infection. J. Clin Microbiol. 49, 3954-3959.

Cloeckaert, A., Grayon, M., Grepinet, O., and Bourmedine, K. S. (2003). Classification of Brucella strains isolated from marine mammals by infrequent restriction site-PCR and development of specific PCR identification tests. Microbes Infect. 5, 593-602.

Cloeckaert, A., Verger, J. M., Grayon, M., and Grepinet, O. (1995). Restriction site polymorphism of the genes encoding the major $25 \mathrm{kDa}$ and $36 \mathrm{kDa}$ outer membrane proteins of Brucella. Microbiology 141, 2111-2121.

Cloeckaert, A., Verger, J. M., Grayon, M., Paquet, J. Y., Garin-Bastuji, B., Foster, G., and Godfroid, J. (2001). Classification of Brucella spp. isolated from marine mammals by DNA polymorphism at the omp2 locus. Microbes Infect. 3, 729-738.

Cowan, D. F. (2004). "A case of culture proven Brucella meningitis in a bottlenose dolphin," in Biennial Meeting, South East Stranding Region, August 5-7 (Wilmington, NC: NMFS).

Dagleish, M. P., Barley, J., Finlayson, J., Reid, R. J., and Foster, G. (2008). Brucella ceti associated pathology in the testicle of a harbour porpoise (Phocoena phocoena). J. Comp. Pathol. 139, 54-59.

Dagleish, M. P., Barley, J., Howie, F. E., Reid, R. J., Herman, J., and Foster, G. (2007). Isolation of Brucella species from a diseased atlanto-occipital joint of an Atlantic whitesided dolphin (Lagenorhynchus acutus). Vet. Rec. 160, 876-878.

Dailey, M., Walsh, M., Odell, D., and Campbell, T. (1991). Evidence of prenatal infection in the bottlenose dolphin (Tursiops truncatus) with the lungworm Halocercus lagenorhynchi (Nematoda: Pseudaliidae). J. Wildl. Dis. 27, 164-165.

Davison, N. J., Cranwell, M. P., Perrett, L. L., Dawson, C. E., Deaville, R., Stubberfield, E. J., Jarvis, D. S., and Jepson, P. D. (2009). Meningoencephalitis associated with Brucella species in a live-stranded striped dolphin (Stenella coeruleoalba) in south-west England. Vet. Rec. 165, 86-89.
Davison, N. J., Perrett, L. L., Law, R. J., Dawson, C. E., Stubberfield, E. J. Monies, R. J., Deaville, R., and Jepson, P. D. (2011). Infection with Brucella ceti and high levels of polychlorinated biphenyls in bottlenose dolphins (Tursiops truncatus) stranded in south-west England. Vet. Rec. 169 14.

Dawson, C. E., Perrett, L. L., Stubberfield, E. J., Stack, J. A., Farrelly, S. S. Cooley, W. A., Davison, N. J., and Quinney, S. (2008a). Isolation and characterization of Brucella from the lungworms of a harbor porpoise (Phocoena phocoena). J. Wildl. Dis. 44, 237-246.

Dawson, C. E., Stubberfield, E. J., Perrett, L. L., King, A. C., Whatmore, A. M., Bashiruddin, J. B., Stack, J. A., and Macmillan, A. P. (2008b). Phenotypic and molecular characterisation of Brucella isolates from marine mammals. BMC Microbiol. 8, 224. doi:10.1186/1471-2180-8-224

Dawson, C. E., Perrett, L. L., Young, E. J., Davison, N. J., and Monies, R. J. (2006). Isolation of Brucella species from a bottlenose dolphin (Tursiops truncatus). Vet. Rec. 158, 831-832.

Deaville, R., and Jepson, P. D. (2009). UK Cetacean Strandings Investigation Programm (CSIP). Annual Report for the Period 1st January31st December 2009. Bristol: Department for Environment Food and Rural Affairs, Natural Environment Group Science Division.

Delpino, M. V., Fossati, C. A., and Baldi, P. C. (2004). Occurrence and potential diagnostic applications of serological cross-reactivities between Brucella and other alphaProteobacteria. Clin. Diagn. Lab. Immunol. 11, 868-873.

Di Guardo, G., Proietto, U., Di Francesco, C. E., Marsilio, F., Zaccaroni, A., Scaravelli, D., Mignone, W., Garibaldi, F., Kennedy, S., Forster, F., Iulini, B., Bozzetta, E. and Casalone, C. (2010). Cerebral toxoplasmosis in striped dolphins (Stenella coeruleoalba) stranded along the Ligurian Sea coast of Italy. Vet. Pathol. 47, 245-253.

Díaz-Aparicio, E., Aragón, V., Marín, C., Alonso, B., Font, M., Moreno, E., Pérez-Ortiz, S., Blasco, J. M., Díaz, R., and Moriyón, I. (1993). Comparative analysis of Brucella serotype $\mathrm{A}$ and M Yersinia enterocolitica O:9 polysaccharides for serological diagnosis of brucellosis in cattle, sheep and goats. J. Clin. Microbiol. 31, 3136-3141.
Díaz-Aparicio, E., Marín, C., AlonsoUrmeneta, B., Aragón, V., PérezOrtiz, S., Pardo, M., Blasco, J. M., Díaz, R., and Moriyón, I. (1994). Evaluation of serological tests for diagnosis of Brucella melitensis infection of goats. J. Clin. Microbiol. 32, 1159-1165.

Dove, V. (2009). Mortality investigation of the Mekong Irrawaddy river dolphin (Orcaella brevirostris) in Cambodia bases on necropsy sample analysis. World Wildl. Fund Tech. Rep. 1-72.

Dubey, J. P., Morales, J. A., Sundar, N., Velmurugan, G. V., GonzálezBarrientos, C. R., Hernández-Mora, G., and Su, C. (2007). Isolation and genetic characterization of Toxoplasma gondii from striped dolphin (Stenella coeruleoalba) from Costa Rica. J. Parasitol. 93, 710-711.

Duignan, P. J., McDonald, W., Mackereth, G., Kittelberger, R., Jamaludin, R., Bando, M., Roe, W., Geschke, K., Jones, G. W., Hutt, A., and Stone, G. (2005). "First report of Brucella sp. in Hector's dolphins (Cephalorhynchus hectori hectori) in New Zealand," in 16th Biennial Conference on the Biology of Marine Mammals, 12-16 December 2005, San Diego, CA.

El-Tras, W. F., Tayel, A. A., Eltholth, M. M., and Guitian, J. (2010). Brucella infection in fresh water fish: evidence for natural infection of Nile catfish, Clarias gariepinus, with Brucella melitensis. Vet. Microbiol. 141, 321-325.

Endo, T., Haraguchi, K., Hotta, Y., Hisamichi, Y., Lavery, S., Dalebout, M. L., and Baker, C. S. (2005). Total mercury, methyl mercury, and selenium levels in the red meat of small cetaceans sold for human consumption in Japan. Environ. Sci. Technol. 39, 5703-5708.

Ewalt, D. R., Payeur, J. B., Martin, B. M., Cummins, D. R., and Miller, G. M. (1994). Characteristics of a Brucella species from a bottlenose dolphin (Tursiops truncatus). J. Vet. Diagn. Invest. 6, 448-452.

Foster, G., Jahans, K. L., Reid, R. J., and Ross, H. M. (1996). Isolation of Brucella species from cetaceans, seals and an otter. Vet. Rec. 138, 583-586.

Foster, G., MacMillan, A. P., Godfroid, J., Howie, F., Ross, H. M., Cloeckaert, A., Reid, R. J., Brew, S., and Patterson, I. A. (2002). A review of Brucella spp. infection of sea mammals with particular emphasis on isolates from Scotland. Vet. Microbiol. 90, 563-580. 
Foster, G., Osterman, B. S., Godfroid, J., Jacques, I., and Cloeckaert, A. (2007). Brucella ceti sp. nov. and Brucella pinnipedialis sp. nov. for Brucella strains with cetaceans and seals as their preferred hosts. Int. J. Syst. Evol. Microbiol. 57, 2688-2693.

Foster, G., Whatmore, A., Koylass, M., Perrett, L., Dagleish, M., and Reid, B. (2011). "Smooth and rough strains of Brucella ceti recovered from different tissues in a stranded harbour porpoise (Phocoena phocoena)," in Brucellosis 2011 International Research Conference, Buenos Aires, 89.

Galatius, A., Sonne, C., Kinze, C. C., Dietz, R., and Jensen, J. E. (2009). Occurrence of vertebral osteophytosis in a museum sample of whitebeaked dolphins (Lagenorhynchus albirostris) from Danish waters. J. Wildl. Dis. 45, 19-28.

García-Rodríguez, J. A., GarcíaSánchez, J. E., Mufioz, Bellido, J. L., Ortiz de la Tabla, V., and Bellido Barbero, J. (1989). Review of pulmonary brucellosis: a case report on brucellar pulmonary empyema. Diagn. Microbiol. Infect. Dis. 11, 53-60.

Gelev, I., and Gelev, E. (1988). A new species of fish-pathogenic bacterium antigenically related to classical Brucellae. Zentralbl. Bakteriol. Mikrobiol. Hyg. A. 269, 1-6.

Gidlewski, T., Cheville, N. F., Rhyan, J. C., Miller, L. D., and Gilsdorf, M. J. (2000). Experimental Brucella abortus induced abortion in a llama: pathologic effects. Vet. Pathol. 3, 77-82.

Godreuil, S., Cohan, F., Shah, H., and Tibayrenc, M. (2005). Which species concept for pathogenic bacteria? An E-Debate. Infect. Genet. Evol. 5, 375-387.

González, L., Patterson, I. A., Reid, R. J., Foster, G., Barberán, M., Blasco, J. M., Kennedy, S., Howie, F. E., Godfroid, J., MacMillan, A. P., Schock, A., and Buxton, D. (2002). Chronic meningoencephalitis associated with Brucella sp. infection in live-stranded striped dolphins (Stenella coeruleoalba). J. Comp. Pathol. 126, 147-152.

González-Barrientos, R., Morales, J. A., Hernández-Mora, G., BarqueroCalvo, E., Guzmán-Verri, C., Chaves-Olarte, E., and Moreno, E. (2010). Pathology of striped dolphins (Stenella coeruleoalba) infected with Brucella ceti. J. Comp. Pathol. 142, 347-352.

Groussaud, P., Shankster, S. J., Koylass, M. S., and Whatmore, A. M. (2007).
Molecular typing divides marine mammal strains of Brucella into at least three groups with distinct host preferences. J. Med. Microbiol. 56, 1512-1518.

Guilbride, P. D., Coyle, T. J., McAnulty, E. G., Barber, L., and Lomax, G. D. (1962). Some pathogenic agents found in hippopotamus in Uganda. J. Comp. Pathol. 72, 137-141.

Guillemin, G. J., and Brew, B. J. (2004). Microglia, macrophages, perivascular macrophages, and pericytes: a review of function and identification. J. Leukoc. Biol. 75, 388-397.

Halling, S. M., Tatum, F. M., and Bricker, B. J. (1993). Sequence and characterization of an insertion sequence, IS711, from Brucella ovis. Gene 133, 123-127.

Harms, C. A., Maggi, R. G., Breitschwerdt, E. B., Clemons-Chevis, C. L., Solangi, M., Rostein, D. S., Fair, P. A., Hansen, L. J., Hohn, A. A., Lovewell, G. N., McLellan, W. A., Pabst, D. A., Rowles, T. K., Schwacke, L. H., Townsend, F. I., and Wells, R. S. (2008). Bartonella species detection in captive, stranded and free-ranging cetaceans. Vet. Res. 39, 59.

Harrison, R. J. (1975). Functional Anatomy of Marine Mammals, Vol. 2. New York: Academic Press.

Hernández-Mora, G., GonzálezBarrientos, R., Morales, J. A., Chaves-Olarte, E., Guzmán-Verri, C., Barquero-Calvo, E., De-Miguel, M. J., Marín, C. M., Blasco, J. M., and Moreno, E. (2008). Neurobrucellosis in stranded dolphins, Costa Rica. Emerging Infect. Dis. 14, 1430-1433.

Hernández-Mora, G., Manire, C. A. González-Barrientos, R., BarqueroCalvo, E., Guzmán-Verri, C., Staggs, L., Thompson, R., Chaves-Olarte, E., and Moreno, E. (2009). Serological diagnosis of Brucella infections in odontocetes. Clin. Vaccine Immunol. 16, 906-915.

Hinchliffe, P. (1984). The detection of complement fixing antibodies by ELISA (COMPELISA) in Brucella serology. Dev. Biol. Stand. 56, 465-469.

Hinchliffe, P. M., and Robertson, L. (1983). Detection of complement fixation by enzyme linked immunosorbant assay (COMPELISA). J. Clin. Pathol. 36, 100-103.

Hof, P. R., Glezer, I. I., Conde, F., Flagg, R. A., Rubin, M. B., Nimchimsky, E. A., and Vogt Weisenhorn, D. M. (1999). Cellular distribution of the calciumbinding proteins parvalbumin, calbindin, and calretinin in the neocortex of mammals: phylogenetic and developmental patterns. J. Chem. Neuroanat. 16 77-116.

Hong, C. B., Donahue, J. M., Giles, R. C. Jr., Poonacha, K. B., Tuttle, P. A., and Cheville, N. F. (1991). Brucella abortus-associated meningitis in aborted bovine fetuses. Vet. Pathol. 28, 492-496.

Hoyt, E., and Iñíguez, M. (2008). The State of Shale Watching in Latin America. Chippenham: WDCS.

Humphreys, F. A., and Moore, T. (1941). Studies relating to Brucella abortus infection I-on the occurrence of the organism in the blood stream. Can J. Comp. Med. Vet. Sci. 5, 5-20.

Jaber, J. R., Pérez, J., Zafra, R., Herráez, P., Rodríguez, F., Arbelo, M., de los Monteros, A. E., and Fernández, A. (2010). Cross-reactivity of anti-human, anti-porcine and antibovine cytokine antibodies with cetacean tissues. J. Comp. Pathol. 143, 45-51.

Jacques, I., Grayon, M., and Verger, J. M. (2007). Oxidative metabolic profiles of Brucella strains isolated from marine mammals: contribution to their species classification. FEMS Microbiol. Lett. 270, 245-249.

Jahans, K. L., Foster, G., and Broughton, E. S. (1997). The characterisation of Brucella strains isolated from marine mammals. Vet. Microbiol.57, 373-382.

Jauniaux, T. P., Brenez, C., Fretin, D., Godfroid, J., Haelters, J., Jacques, T., Kerckhof, F., Mast, J., Sarlet, M., and Coignoul, F. L. (2010). Brucella ceti infection in harbor porpoise (Phocoena phocoena). Emerging Infect. Dis. 16, 1966-1968.

Jepson, P. D. (2005). Cetaceans Strandings Investigation and Coordination in the UK, Final Report to DEFRA for the period 1st January 2000-31st December 2004. Defra Publications London: Department for Environment Food and Rural Affairs.

Jepson, P. D., Brew, S., MacMillan, A. P. Baker, J. R., Barnett, J., Kirkwood, J. K., Kuiken, T., Robinson, I. R., and Simpson, V. R. (1997). Antibodies to Brucella in marine mammals around the coast of England and Wales. Vet. Rec. 141, 513-515.

Jepson, P. D., and Deaville, R. (2008). "Investigation of the common dolphin mass stranding event in Cornwall," in UK Cetacean Strandings Investigation Programm (CSIP), London.

Johnson, B., Mosier, D. A., Morton, R. J., and Confer, A. W. (1994). Experimental Brucella abortus strain
19 arthritis in young cattle. J. Vet. Diagn. Invest. 6, 56-61.

Kennedy, S. (1998). Morbillivirus infections in aquatic mammals. J. Comp. Pathol. 119, 201-225.

Kondo, S., Haishima, Y., Ishida, K., Isshiki, Y., and Hisatsune, K. (2000). The O-polysaccharide of lipopolysaccharide isolated from Vibrio fluvialis $\mathrm{O} 19$ is identical to that of Vibrio biosero group 1875 variant. Microbiol. Immunol. 44, 941-944.

Kronvall, G., Seal, U. S., Finstad, J., and Williams, R. C. Jr. (1970). Phylogenetic insight into evolution of mammalian Fc fragment of gamma $\mathrm{G}$ globulin using staphylococcal protein A. J. Immunol. 104, 140-147.

Kumar, S., and Hedges, S. B. (1998). A molecular timescale for vertebrate evolution. Nature 392, 917-920.

Le Flèche, P., Jacques, I., Grayon, M., Al Dahouk, S., Bouchon, P., Denoeud, F., Nöckler, K., Neubauer, H., Guilloteau, L. A., and Vergnaud, G. (2006). Evaluation and selection of tandem repeat loci for a Brucella MLVA typing assay. BMC Microbiol. 6, 9. doi:10.1186/1471-2180-6-9

Malakoff, D. (2001). Marine mammals. Scientists use strandings to bring species to life. Science 293, 1754-1757.

Manire, A. C., Barrios, N., Socha, V., Byrd, L., Hernández-Mora, G., deBorja, K., Rostein, D., Kinsel, M. J., Terio, K. A. (2007). "Brucellar meningitis in an atlantic bottlenose dolphin, Tursiops truncatus," in Proceedings of 38th Annual Conference International Association for Aquatic Animal Medicine, May 5th- 9th, 2007, Lake Buena Vista, FL.

Maquart, M., Le Flèche, P., Foster, G., Tryland, M., Ramisse, F., Djønne, B., Al Dahouk, S., Jacques, I., Neubauer, H., Walravens, K., Godfroid, J., Cloeckaert, A., and Vergnaud, G. (2009a). MLVA16 typing of 295 marine mammal Brucella isolates from different animal and geographic origins identifies 7 major groups within Brucella ceti and Brucella pinnipedialis. BMC Microbiol. 9, 145. doi:10.1186/1471-2180-9-145

Maquart, M., Zygmunt, M. S., and Cloeckaert, A. (2009b). Marine mammal Brucella isolates with different genomic characteristics display a differential response when infecting human macrophages in culture. Microbes Infect. 11, 361-366. 
Maratea, J., Ewalt, D. R., Frasca, S. Jr., Dunn, J. L., De Guise, S., Szkudlarek, L., St. Aubin, S. J., and French, R. A. (2003). Evidence of Brucella sp. infection in marine mammals stranded along the coast of southern New England. J. Zoo Wildl. Med. 34, 256-261.

Marco, J., González, L., Cuervo, L. A., Beltrán-de-Heredia, F., Barberán, M., Marín, C., and Blasco, J. M. (1994). Brucella ovis infection in two flocks of sheep. Vet. Rec. 135, 254-256.

Marin, C. M., Alabart, J. L., and Blasco, J. M. (1996). Effect of antibiotics contained in two Brucella selective media on growth of $B$. abortus, $B$. melitensis and B. ovis. J. Clin. Microbiol. 34, 426-428.

Marvulo, M. F. V., Da Silva, V. M. F., Martin, A. R., D'Affonseca Neto, J. A., Rosas, F. C. W., Nascimento, C. C., Morais, Z. M., Vasconcellos, S. A., Ferreira Neto, J. S., and Silva, J. C. R. (2003). "Serosurvey for antibodies against Leptospira sp. and Brucella sp. in free living Amazon river dolphin (Inia geoffrensis) and captive amazonian manataees (Trichechus inunguis)," in 15th Biennial Conference on the Biology of Marine Mammals, Greensboro, NC.

May-Collado, L. J., and Agnarsson, I. (2006). Cytochrome b and Bayesian inference of whale phylogeny. Mol. Phylogenet. Evol. 38, 344-354.

McCormick, J. G. (1969). Relationship of sleep, respiration, and anesthesia in the porpoise: a preliminary report. Proc. Natl. Acad. Sci. U.S.A. 62, 697-703.

McDonald, W. L., Jamaludin, R., Mackereth, G., Hansen, M., Humphrey, S., Short, P., Taylor, T., Swingler, J., Dawson, C. E., Whatmore, A. M., Stubberfield, E., Perrett, L. L., and Simmons, G. (2006). Characterization of a Brucella sp. strain as a marinemammal type despite isolation from a patient with spinal osteomyelitis in New Zealand. J. Clin. Microbiol. 44, 4363-4370.

Mead, J. G. (2008). "Gastrointestinal tract," in Encyclopedia of Marine Mammals, 2nd Edn, eds W. F. Perrin, B. Würsing, and J. G. M. Thewissen (New York: Academic Press), 72-477.

Meegan, J., Field, C., Sidor, I., Romano, T., Casinghino, S., Smith, C. R., Kashinsky, L., Fair, P. A., Bossart, G., Wells, R., and Dunn, J. L. (2010). Development, validation, and utilization of a competitive enzymelinked immunosorbent assay for the detection of antibodies against
Brucella species in marine mammals. J. Vet. Diagn. Invest. 22, 856-862.

Meyer, M. E. (1990). "Evolutionary development and taxonomy of the genus Brucella," in Advances in Brucellosis Research, ed. L. G. Adams (College Station: Texas A\&M University Press), 12-35.

Miller, D. L. (2007). Reproductive Biology and Phylogeny of Cetacea: Whales, Dolphins, and Porpoises. Enfield: Science Publishers, Inc.

Miller, W. G., Adams, L. G., Ficht, T. A., Cheville, N. F., Payeur, J. P., Harley, D. R., House, C., and Ridgway, S. H. (1999). Brucella-induced abortions and infection in bottlenose dolphins (Tursiops truncatus). J. Zoo Wildl. Med. 30, 100-110.

Moreno, E. (1998). Genome evolution within the alpha Proteobacteria: why do some bacteria not possess plasmids and others exhibit more than one different chromosome? FEMS Microbiol. Rev. 22, 255-275.

Moreno, E., Cloeckaert, A., and Moriyón, I. (2002). Brucella evolution and taxonomy. Vet. Microbiol. 90, 209-227.

Moreno, E., and Moriyón, I. (2002). Brucella melitensis: a nasty bug with hidden credentials for virulence. Proc. Natl. Acad. Sci. U.S.A. 99, 1-3.

Moreno, E., and Moriyón, I. (2006). "The genus Brucella," in The Prokaryotes, eds M. Dworkin, S. Falkow, E. Rosenberg, K.-H. Schleifer, and E. Stackebrant (New York: Springer-Verlag), 315-456.

Muñoz, P. M., García-Castrillo, G., López-García, P., González-Cueli, J. C., De Miguel, M. J., Marín, C. M., Barberán, M., and Blasco, J. M. (2006). Isolation of Brucella species from alive-stranded striped dolphin (Stenella coeruleoalba) in Spain. Vet. Rec. 158, 450-451.

Neimanis, A. S., Koopman, H. N., Westgate, A. J., Nielsen, K., and Leighton, F. A. (2008). Evidence of exposure to Brucella sp. in harbor porpoises (Phocoena phocoena) from the Bay of Fundy, Canada. J. Wildl. Dis. 44, 480-485.

Nielsen, O., Stewart, R. E. A., Nielsen, K., Measures, L., and Duignan, P. (2001). Serologic survey of Brucella spp. antibodies in some marine mammals of North America. J. Wildl. Dis. 37, 89-100

Nikaido, M., Matsuno, F., Hamilton, H., Brownell, R. L. Jr., Cao, Y., Ding, W., Zuoyan, Z., Shedlock, A. M., Fordyce, R. E., Hasegawa, M., and Okada, N. (2001). Retroposon analysis of major cetacean lineages: the monophyly of toothed whales and the paraphyly of river dolphins. Proc. Natl. Acad. Sci. U.S.A. 98 7384-7389.

Nollens, H. H., Ruiz, C., Walsh, M. T. Gulland, F. M., Bossart, G., Jensen, E. D., McBain, J. F., and Wellehan, J. F. (2008). Cross-reactivity between immunoglobulin $\mathrm{G}$ antibodies of whales and dolphins correlates with evolutionary distance. Clin. Vaccine Immunol. 15, 1547-1554.

Obiako, O. R., Ogoina, D., Danbauchi, S. S., Kwaifa, S. I., Chom, N. D., and Nwokorie, E. (2010). Neurobrucellosis - a case report and review of literature. Niger. J. Clin. Pract. 13, 347-350.

Ochrymowych, C., and Lambertsen, R. H. (1984). Anatomy and vasculature of a minke whale heart. Am. J. Anat. 169, 165-175.

Oelschläger, H. H., Ridgway, S. H., and Knauth, M. (2010). Cetacean brain evolution: Dwarf sperm whale (Kogia sima) and common dolphin (Delphinus delphis) - an investigation with high-resolution 3D MRI Brain Behav. Evol. 75, 33-62.

Ohishi, K., Fujise, Y., and Maruyama, T. (2008). Brucella spp. in the western North Pacific and Antarctic cetaceans: a review. J. Cetacean Res. Manag. 10, 67-72.

Ohishi, K., Katsumata, E., Uchida, K., and Maruyama, T. (2007). Two stranded pygmy with anti- Brucella antibodies in Japan. Vet. Rec. 160, 628-629.

Ohishi, K., Takishita, K., Kawato, M., Zenitani, R., Bando, T., Fujise, Y., Goto, Y., Yamamoto, S., and Maruyama, T. (2004). Molecular evidence of new variant Brucella in North Pacific common minke whales. Microbes Infect. 6, 199-204.

Ohishi, K., Zenitani, R., Bando, T., Goto, Y., Uchida, K., Maruyama, T., Yamamoto, S., Miyazaki, N., and Fujise, Y. (2003). Pathological and serological evidence of Brucellainfection in baleen whales (Mysticeti) in the western North Pacific. Comp. Immunol. Microbiol. Infect. Dis. 26, 125-136.

Oliveira, J. B., Morales, J. A., González-Barrientos, R. C., Hernández-Gamboa, J., and Hernández-Mora, G. (2011). Parasites of cetaceans stranded on the Pacific coast of Costa Rica. Vet. Parasitol. 182, 319-328.

Omata, Y., Umeshita, Y., Watarai, M., Tachibana, M., Sasaki, M., Murata, K., and Yamada, T. K. (2006). Investigation for presence of Neospora caninum, Toxoplasma gondii and Brucella-species infection in killer whales (Orcinus orca) massstranded on the coast of Shiretoko, Hokkaido, Japan. J. Vet. Med. Sci. 68, 523-526.

Orams, M. B. (1997). Historical accounts of human-dolphin interaction and recent developments in wild dolphin based tourism in Australasia. Tourism Manag. 18, 317-326.

Özbek, C., Yetkin, U., Yürekli, I., Bademci, M., and Gürbüz, A. (2007). Development of commissural perforation of an aortic valve in Brucella endocarditis with giant vegetation. Internet J. Thorac. Cardiovasc. Surg. 10,1 .

Perrett, L. L., Brew, S. D., Stack, J. A., MacMillan, A. P., and Bashiruddin, J. B. (2004a). Experimental assessment of the pathogenicity of Brucella strains from marine mammals for pregnant sheep. Small Rumin. Res. 51, 221-228.

Perrett, L. L., Dawson, C. E., Davison, N., and Quinney, S. (2004b). Brucella infection of lungworms from a harbour porpoise. Vet. Rec. 154, 800.

Perrin, W. F., Wursing, B., and Thewissen, J. G. M. (2008). Encyclopedia of Marine Mammals, 2nd Edn, New York: Academic Press.

Ponganis, P. J. (2008a). "Breathing," in Encyclopedia of Marine Mammals, 2nd Edn, eds W. F. Perrin, B. Würsing, and J. G. M. Thewissen (New York: Academic Press), 230.

Ponganis, P. J. (2008b). "Circulatory system. Cetacean prenatal development," in Encyclopedia of Marine Mammals, 2nd Edn, eds W. F. Perrin, B. Würsing, and J. G. M. Thewissen (New York: Academic Press), 230-234.

Prenger-Berninghoff, E., Siebert, U., Stede, M., König, A., Weiß, R., and Baljer, G. (2008). Incidence of Brucella species in marine mammals of the German North Sea. Dis. Aquat. Org. 81, 65-71.

Rahman, A., Burma, O., Felek, S. and Yekeler, H. (2001). Atrial septal defect presenting with Brucella endocarditis. Scand. J. Infect. Dis. 33, 776-777.

Reidenberg, J. S., and Laitman, J. T. (2008). "Cetacean prenatal development," in Encyclopedia of Marine Mammals, 2nd Edn, eds W. F. Perrin, B. Würsing, and J. G. M. Thewissen (New York: Academic Press), 220-230.

Reyes, G. G., Verdugo, J. M., Cassin, D., and Carvajal, R. (2002). Pollution by polychlorinated biphenyls in an 
estuary of the Gulf of California. Their toxicity and bioaccumulation in shrimp Litopenaeus vannamei. Mar. Pollut. Bull. 46, 959-963.

Rhyan, J. C., Gidlewski, T., Ewalt, D. R., Hennager, S. G., Lambourne, D. M., and Olsen, S. C. (2001). Seroconversion and abortion in cattle experimentally infected with $\mathrm{Bru}$ cella sp. isolated from a Pacific harbor seal (Phoca vitulina richardsi). J. Vet. Diagn. Invest. 13, 379-382.

Rhyan, J. C., Holland, S. D., Gidlewski, T., Saari, D. A., Jense, A. E., Ewalt, D. R., Hennager, S. G., Olsen, S. C., and Cheville, N. F. (1997). Seminal vesiculitis and orchitis caused by Brucella abortus biovar 1 in young bison bulls from South Dakota. J. Vet. Diagn. Invest. 9, 368-374.

Roop, R. M. II, Gaines, J. M., Anderson, E. S., Caswell, C. C., and Martin, D. W. (2009). Survival of the fittest: how Brucella strains adapt to their intracellular niche in the host. Med. Microbiol. Immunol. 198, 221-238.

Ross, H. M., Jahans, K. L., MacMillan, A. P., Reid, R. J., Thompson, P. M., and Foster, G. (1996). Brucella species infection in North Sea seal and cetacean populations. Vet. Rec. $138,647-648$.

Ross, H. M., and Wilson, B. (1996). Violent interactions between bottlenose dolphins and harbour porpoises. Proc. Biol. Sci. 263, 283-286.

Sabin, R. C., Jepson, P. D., Reid, R. J., Chimonides, P. D. J., Deaville, R., Patterson, I. A. P., and Spurrier, C. J. (2002). Trends in Cetacean Strandings Around the UK Costline and Marine Mammal Post/Mortem Investigations for the Year 2002 Consultancy Report, Contract CRO 238. London: Department for Environment, Food and Rural Affairs (DEFRA), The Natural History Museum.

Salem, S. F., and Mohsen, A. (1997). Brucellosis in fish. Vet. Med. (Praha) 42, 5-7.
Santos, M. B., and Pierce, G. J. (2003). The diet of harbour porpoise (Phocoena phocoena) in the northeast Atlantic. Oceanogr. Mar. Biol. Annu. Rev. 41, 355-390.

Smith, B. D., Aminul-Haque, A. K. M., Shakhawat-Hossain, M., and Khan, A. (1998). PROFILE: river dolphins in Bangladesh: conservation and the effects of water development. Environ. Manage. 22, 323-335.

Sohn, A. H., Probert, W. S., Glaser, C. A., Gupta, N., Bollen, A. W., Wong, J. D., Grace, E. M., and Mc Donald, W. C. (2003). Human neurobrucellosis with intracerebral granuloma caused by a marine mammal $\mathrm{Bru}$ cella spp. Emerging Infect. Dis. 9, 485-488.

Soto, S., González, B., Willoughby, K., Maley, M., Olvera, A., Kennedy, S., Marco, A., and Domingo, M. (2011). Systemic herpes virus and Morbillivirus co-infection in a striped dolphin (Stenella coeruleoalba). J. Comp. Pathol. [Epub ahead of print].

Spink, W. W. (1956). The Nature of Brucellosis. Minnesota: The University of Minnesota Press.

Staley, J. T. (2006). The bacterial species dilemma and the genomicphylogenetic species concept. Philos. Trans. R. Soc. Lond. B Biol. Sci. 361, 1899-1909.

Stewart, R. E. A., and Stewart, B. E. (2008). "Female reproductive systems," in Encyclopedia of Marine Mammals, 2nd Edn, eds W. F. Perrin, B. Würsing, and J. G. M. Thewissen (New York: Academic Press), 423-429.

Tachibana, M., Watanabe, K., Kim, S., Omata, Y., Murata, K., Hammond, T., and Watarai, M. (2006). Antibodies to Brucella spp. in Pacific bottlenose dolphins from the Solomon Islands. J. Wildl. Dis. 42, 412-414.

Tryland, M., Kleivane, L., Alfredsson, A., Kjeld, M., Arnason, A., Stuen, S., and Godfroid, J. (1999). Evidence of Brucella infection in marine mammals in the North Atlantic Ocean. Vet. Rec. $144,588-592$.

Uhart, M., Rowntree, V. J., Mohamed, N., Pozzi, L., La Sala, L., Andrejuk, J., Musmeci, L., Franco, M., Sironi, M., Sala, J. E., McAloose, D. Moore, M., Tohuey, K., McLellan, W. A., and Rowles, T. (2009) Strandings of southern right whales (Eubalaena australis) at Península Valdés, Argentina from 2003-2007. J. Cetacean Res. Manag. 1, 1-9.

Van Bressem, M. F., Raga, J. A., Di Guardo, G., Jepson, P. D., Duignan, P. J., Siebert, U., Barrett, T., Santos, M. C., Moreno, I. B., Siciliano, S., Aguilar, A., and Van Waerebeek, K. (2009). Emerging infectious diseases in cetaceans worldwide and the possible role of environmental stressors. Dis. Aquat. Org. 86 143-157.

Van Bressem, M. F., Van Waerebeek, K., Raga, J. A., Godfroid, J., Brew, S. D., and Mac Millan, A. P. (2001). Serological evidence of Brucella species infection in odontocetes from the South Pacific and the Mediterranean. Vet. Rec. 148, 657-661.

Warstzok, D. (2008). "Breathing," in Encyclopedia of Marine Mammals, 2nd Edn, eds W. F. Perrin, B. Würsing, and J. G. M. Thewissen (New York: Academic Press), 152-156

Whatmore, A. M., Dawson, C. E., Groussaud, P., Koylass, M. S., King, A. C., Shankster, S. J., Sohn, A. H., Probert W. S., and McDonald, W. L. (2008). Marine mammal Brucella genotype associated with zoonotic infection. Emerging Infect. Dis. 14, 517-518.

Whatmore, A. M., Perrett, L. L., and Macmillan, A. P. (2007). Characterisation of the genetic diversity of Brucella by multilocus sequencing. BMC Microbiol. 7, 34 . doi:10.1186/1471-2180-7-34

Whatmore, A. M., Shankster, S. J., Perrett, L. L., Murphy, T. J., Brew, S. D., Thirlwall, R. E., Cutler, S. J., and MacMillan, A. P. (2006). Identification and characterization of variable-number tandem-repeat markers for typing of Brucella spp. J. Clin. Microbiol. 44, 1982-1993.
Xavier, M. N., Paixão, T. A., Poester, F. P., Lageand, A. P., and Santos, R. L. (2009). Pathological, immunohistochemical and bacteriological study of tissues and milk of cows and fetuses experimentally infected with Brucella abortus. J. Comp. Pathol. 140, 149-157.

Zygmunt, M. S., Blasco, J. M., Letesson, J. J., Cloeckaert, A., and Moriyón, I. (2009). DNA polymorphism analysis of Brucella lipopolysaccharide genes reveals marked differences in O-polysaccharide biosynthetic genes between smooth and rough Brucella species and novel species-specific markers. BMC Microbiol. 13, 9. doi:10.1186/1471-2180-9-92

Zygmunt, M. S., Maquart, M., Bernardet, N., Doublet, B., and Cloeckaert, A. (2010). Nove IS711-specific chromosomal locations useful for identification and classification of marine mammal Brucella strains. J. Clin. Microbiol. 48, 3765-3769.

Conflict of Interest Statement: The authors declare that the research was conducted in the absence of any commercial or financial relationships that could be construed as a potential conflict of interest.

Received: 13 October 2011; accepted: 12 January 2012; published online: 06 February 2012.

Citation: Guzmán-Verri C, GonzálezBarrientos $R$, Hernández-Mora $G$, Morales J-A, Baquero-Calvo E, ChavesOlarte E and Moreno E (2012) Brucella ceti and brucellosis in cetaceans. Front. Cell. Inf. Microbio. 2:3. doi: 10.3389/fcimb.2012.00003

Copyright (C) 2012 Guzmán-Verri, González-Barrientos, Hernández-Mora, Morales, Baquero-Calvo, Chaves-Olarte and Moreno. This is an open-access article distributed under the terms of the Creative Commons Attribution Non Commercial License, which permits non-commercial use, distribution, and reproduction in other forums, provided the original authors and source are credited. 